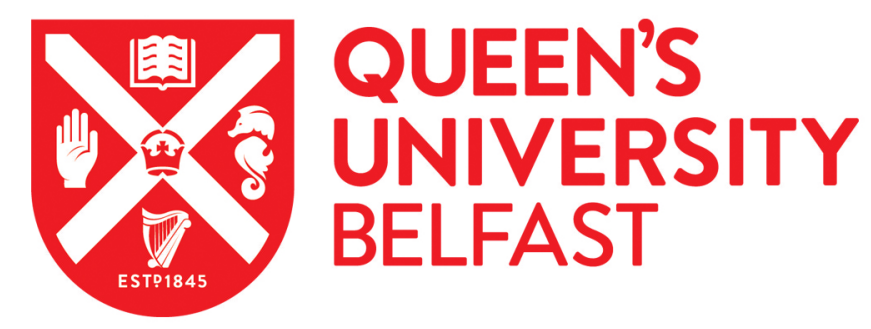

\title{
Fourier transform emission spectroscopy and ab initio calculations on the visible spectrum of AID+
}

Szajna, W., Hakalla, R., Moore, K., \& Lane, I. C. (2018). Fourier transform emission spectroscopy and ab initio calculations on the visible spectrum of AID+. Journal of Quantitative Spectroscopy \& Radiative Transfer, 221, 118-128. https://doi.org/10.1016/j.jqsit.2018.09.028

Published in:

Journal of Quantitative Spectroscopy \& Radiative Transfer

Document Version:

Peer reviewed version

Queen's University Belfast - Research Portal:

Link to publication record in Queen's University Belfast Research Portal

\section{Publisher rights}

Copyright 2018 Elsevier.

This manuscript is distributed under a Creative Commons Attribution-NonCommercial-NoDerivs License

(https://creativecommons.org/licenses/by-nc-nd/4.0/), which permits distribution and reproduction for non-commercial purposes, provided the author and source are cited.

\section{General rights}

Copyright for the publications made accessible via the Queen's University Belfast Research Portal is retained by the author(s) and / or other copyright owners and it is a condition of accessing these publications that users recognise and abide by the legal requirements associated with these rights.

Take down policy

The Research Portal is Queen's institutional repository that provides access to Queen's research output. Every effort has been made to ensure that content in the Research Portal does not infringe any person's rights, or applicable UK laws. If you discover content in the Research Portal that you believe breaches copyright or violates any law, please contact openaccess@qub.ac.uk. 


\title{
Fourier transform emission spectroscopy and ab initio calculations on the visible spectrum of $\mathrm{AlD}^{+}$
}

\author{
Wojciech Szajna ${ }^{\mathrm{a} *}$ \\ Rafał Hakalla \\ a Materials Spectroscopy Laboratory, Department of Experimental Physics, Faculty of \\ Mathematics and Natural Science, University of Rzeszów, Pigonia 1 Street, 35-959 \\ Rzeszów, Poland \\ Keith Moore ${ }^{\mathrm{b}}$ \\ Ian C. Lane ${ }^{b}$ \\ ${ }^{b}$ School of Chemistry and Chemical Engineering, Queen's University Belfast, Stranmillis \\ Road, Belfast BT9 $5 A G, U K$
}

\begin{abstract}
The spectrum of the $\mathrm{AlD}^{+}$isotopologue has been investigated at high resolution in the 27,000 - 29,000 $\mathrm{cm}^{-1}$ region using a Fourier transform emission spectroscopy technique. The $\mathrm{AlD}^{+}$molecules were produced within a water-cooled aluminum hollow-cathode lamp in the presence of 1.5 Torr of $\mathrm{Ne}$ and 0.8 Torr of $\mathrm{ND}_{3}$. The $(0,0)$ and $(1,1)$ bands belonging to the $\mathrm{A}^{2} \Pi-\mathrm{X}^{2} \Sigma^{+}$system were recorded with an instrumental resolution of $0.03 \mathrm{~cm}^{-1}$. In total, almost 500 rotational frequencies were measured with an absolute accuracy of about $0.005 \mathrm{~cm}^{-1}$. It improved the experimental accuracy of the determined frequencies by the factor 10 compared to the previous work [J Phys B: Mol Phys 1984;17:L861-L866]. The rotational analysis has shown irregularities in the $\Lambda$ - doubling splitting of the $\mathrm{A}^{2} \Pi v=0,1$. Consequently, the $\mathrm{A}^{2} \Pi$ state has been represented by the rotational term values, while the regular $\mathrm{X}^{2} \Sigma^{+}$state by the molecular constants. The causes of the irregulari-
\end{abstract}

\footnotetext{
*Corresponding author.

Email addresses: szajna@ur.edu.pl (Wojciech Szajna ${ }^{\mathrm{a}}$ )
} 
ties were identified in the interaction between the $\mathrm{A}^{2} \Pi$ and the $\mathrm{B}^{2} \Sigma^{+}$states, which lies about $3720 \mathrm{~cm}^{-1}$ above. Supporting ab initio quantum chemical calculations, including spin-orbit effects, reproduce the observed spectroscopic constants including the small energy splittings due to spin-rotation interactions (for ${ }^{2} \Sigma^{+}$states) and $\Lambda$-doubling.

Key words: $\mathrm{AlD}^{+}$isotopologue, Visible spectrum, FT spectroscopy, Molecular parameters, $\Lambda$-doubling, ab initio calculations, spin-orbit coupling, excited state lifetimes, laser cooling

PACS: 33.20Kf, Visible spectra

\section{Introduction}

There has been a growing interest recently in the metal-bearing diatomic hydrides, and their ions, for the production of laser cooled molecules [1, 2]. From this perspective, the $\mathrm{AlH}^{+}$molecular ion is a very promising candidate, especially using the very diagonal $\mathrm{A}^{2} \Pi-\mathrm{X}^{2} \Sigma^{+}$transition $[3,4,5,6]$. In the latest reported experiments [6], broad-band laser cooling of $\mathrm{AlH}^{+}$cations in a linear Paul trap has achieved rotational temperatures around $3.8 \mathrm{~K}$ with $95.4 \%$ of the population in the ground $v=0, N=0$ state.

In this paper, we report the first Fourier transform (FT) spectroscopy of the $\mathrm{A}^{2} \Pi-\mathrm{X}^{2} \Sigma^{+}$system of $\mathrm{AlD}^{+}$together with advanced ab initio calculations for this transition. The experimental part is a continuation of our recent work on the emission spectra of $\mathrm{AlH}[7,8,9,10], \mathrm{AlH}^{+}[11]$ and $\mathrm{AlD}[12,13]$. The present high-quality FT data improves experimental information about $\mathrm{A}^{2} \Pi$ and $\mathrm{X}^{2} \Sigma^{+}$states of $\mathrm{AlD}^{+}$significantly. It should be noted that, only one experimental study on the $\mathrm{AlD}^{+}$ion of Balfour and Lindgren [14] has been reported to date. In this classic emission experiment, a very wide spectrum of the $\mathrm{A}-\mathrm{X}(0,0)$ and $(1,1)$ bands was registered with reciprocal dispersion of $0.5 \AA / \mathrm{mm}$ and estimated absolute accuracy of the measured transition frequencies $0.03 \mathrm{~cm}^{-1}$ for the best lines. The former study provided the first estimated values for the main molecular constant of the $\mathrm{A}^{2} \Pi v=0,1$ and $\mathrm{X}^{2} \Sigma^{+} v=0,1$ levels of $\mathrm{AlD}^{+}$.

The first theoretical study on $\mathrm{AlH}^{+}$by Klein et al. [15] dealt with the first three electronic states and used the equivalent of a modern triple-zeta basis set (highest angular function $l=3$ ) similar to cc-pVTZ [16], though with an additional rather diffuse $p$-function. Potential energy curves were computed at the Multi Configurational Self-Consistant Field (MCSCF)[17] level that 
neglects dynamic electron correlation, along with permanent dipole moment functions (DMFs) and Transition Dipole Moments (TDMs) for the $\mathrm{X}^{2} \Sigma^{+}$, $\mathrm{A}^{2} \Pi$ and $\mathrm{B}^{2} \Sigma^{+}$states between $2-10 \mathrm{a}_{0}$. Using this information the authors simulated the vibronic bands for both the $\mathrm{A}^{2} \Pi-\mathrm{X}^{2} \Sigma^{+}$and $\mathrm{B}^{2} \Sigma^{+}-\mathrm{X}^{2} \Sigma^{+}$ emission spectra and estimated the Einstein $\mathrm{A}$-coefficient at the band head for the former transition as $3.8 \times 10^{6} \mathrm{~s}^{-1}$.

It would take 30 years before a complete electron-correlation treatment was conducted on the lowest electronic states in $\mathrm{AlH}^{+}$. A calculation of the spin-orbit splitting in the $\mathrm{A}^{2} \Pi$ state was conducted by Gui-Xia [18] using perturbation theory on a limited configuration interaction wavefunction though the splitting was some $60 \%$ larger than the experimental value. As part of a study on laser cooling molecular ions, Nguyen et al. [3] conducted very detailed calculations on the lowest three doublet states of $\mathrm{AlH}^{+}$ at the Multi-reference Configuration Interaction (MRCI) level (including spin-orbit coupling) and computed the lifetimes and branching ratios for decay of the $\mathrm{A}^{2} \Pi$ state. The atomic orbitals were described using the larger cc-pCVQZ basis set of Peterson et al. [19] to include core-valence correlation effects. Spectroscopic constants for all three states were produced though the analysis essentially required neglecting the unpaired molecular spin. Later, the two-photon dissociation of the ion was studied by the same group [5], this time the lowest five $\mathrm{AlH}^{+}$doublet states calculated with the same basis set. They calculated the absorption cross-sections using their $a b$ initio TDMs but did not present any new spectroscopic constants. No previous theoretical work has treated the rovibronic levels of the $\mathrm{AlD}^{+}$radical.

The major objectives of this work is to determine improved values for the transition frequencies (wavenumbers), refresh the molecular constants for the ground $\mathrm{X}^{2} \Sigma^{+}$state and obtain new rotational term values for the excited $\mathrm{A}^{2} \Pi$ state of $\mathrm{AlD}^{+}$. Moreover, detailed analysis of the current data has shown anomalous $\Lambda$-doubling features in the $\mathrm{A}^{2} \Pi v=0,1$ levels. Furthermore, theoretical potential energy curves are presented, based on MRCI calculations using the large AV5Z basis set. The lowest ro-vibrational levels for the $\mathrm{X}^{2} \Sigma^{+}, \mathrm{A}^{2} \Pi$ and $\mathrm{B}^{2} \Sigma^{+}$states of the $\mathrm{AlD}^{+}$ion are determined and the spectroscopic constants found, including those describing the spin-rotation splitting. Spin-orbit coupling effects are also included (as are all the quartet states correlating the lowest excited dissociation limit for the first time) and calculations performed on the decay processes important for the low lying $\mathrm{A}^{2} \Pi$ and $\mathrm{B}^{2} \Sigma^{+}$states, taking into account the presence of the molecular 
spin. In addition, the present calculations simulate the $\Lambda$-doubling observed.

\section{Experimental details}

The emission spectrum of $\mathrm{AlD}^{+}$was produced in an aluminum water-cooled hollow-cathode lamp. The cathode was prepared by inserting a $20 \mathrm{~mm}$ long aluminum cylinder (with $3.5 \mathrm{~mm}$ diameter hole) into a brass cylinder in such a way that there was uniform contact between the aluminum and the brass walls. The outside diameter of the brass cylinder is about $2 \mathrm{~mm}$ smaller than the inside diameter of the glass flange. Thanks to this design, the discharge room is isolated from the joint between the cathode and the glass [20]. This type of hollow-cathode lamp can easily be run with high current value (up to $500 \mathrm{~mA}$ in the present tests) without any risk of arcing between the anode and the brass cylinder .

The lamp, filled with a static mixture of helium $(\sim 1.5$ Torr $)$ and deuterated ammonia, was operated at $600 \mathrm{~V}$ with $250 \mathrm{~mA}$ current. The $\mathrm{AlH}^{+}$ bands are a permanent feature of the spectrum, with or without any additional hydrogen source inside the lamp. Consequently, in the preliminary experiments, we were able to record good quality $\mathrm{AlH}^{+} \mathrm{A}-\mathrm{X}(0,0)$ and $(1,1)$ bands with the best signal-to-noise ratio $(\mathrm{SNR})$ of $\sim 70: 1$. The constant electric discharge (of about 20 hours) as well as a gradual addition of $\mathrm{ND}_{3}$ (up to the effective pressure of $\sim 0.8$ Torr) caused the decreasing of the intensity of the $\mathrm{AlH}^{+}$spectrum. Finally, we obtained the satisfied intensity ratio of the $\mathrm{AlD}^{+}: \mathrm{AlH}^{+}$lines of $\sim 1: 0.75$ (see Fig. 1).

A $1.71-\mathrm{m}$ FT spectrometer operated under vacuum conditions (pressure below 0.003 mbar) was used to record the visible (VIS) spectrum of $\mathrm{AlD}^{+}$. A VIS-wavelength quartz beamsplitter and a photomultiplier tube running in integration mode were used to record the spectrum in the 11,000-32, 000 $\mathrm{cm}^{-1}$ spectral region. The spectra bandpass was limited to $17,700-32,000$ $\mathrm{cm}^{-1}$ by a $575 \mathrm{~nm}$ shortpass filter in order to block out the strong Ne lines. In total, 128 scans were co-added in $\sim 2.5 \mathrm{~h}$ of integration at an instrumental resolution of $0.03 \mathrm{~cm}^{-1}$.

The program included in the Opus ${ }^{\mathrm{TM}}$ software package [21] was used for the line measurement. The Voigt lineshape function was fitted to the spectral line profiles. The spectrum was calibrated using the Ne atomic lines [22]. The absolute accuracy of the wavenumber scale is expected to be better than $0.002 \mathrm{~cm}^{-1}$. The strong, isolated lines of the $Q_{11}$ branch of the $(0,0)$ band appear with maximum SNR of $\sim 50: 1$ and the typical width of $\sim 0.11$ 
$\mathrm{cm}^{-1}$. At the same time, the SNR for the strongest $Q_{11}$ lines of the prominent $\mathrm{A}^{1} \Pi-\mathrm{X}^{1} \Sigma^{+}(0,0)$ band of AlD [13] is about $3000: 1$.

The estimated absolute accuracy of our measurements of the $\mathrm{AlD}^{+}$transitions is $0.005 \mathrm{~cm}^{-1}$ for the strong and unblended lines. For weaker lines, the poor SNR and blending caused by overlapping lines limited the accuracy of measurement to $0.01 \mathrm{~cm}^{-1}$ (see Table 1 and 2). Currently determined transition frequencies are blue-shifted, by about $0.4 \mathrm{~cm}^{-1}$, relative to those reported by Balfour and Lindgren [14] obtained from a non-FT spectrometer in which the $\mathrm{AlD}^{+}$spectrum has been calibrated using Fe atomic lines. 
Table 1: Transition frequencies (in $\mathrm{cm}^{-1}$ ) of the $\mathrm{A}^{2} \Pi-\mathrm{X}^{2} \Sigma^{+}(0,0)$ band of $\mathrm{AlD}^{+} .{ }^{\mathrm{a}}$

\begin{tabular}{|c|c|c|c|c|c|c|}
\hline$J$ & $R_{11 e e}$ & $R_{22 f f}$ & $Q_{11 f e}$ & $Q_{22 e f}$ & $P_{11 e e}$ & $P_{22 f f}$ \\
\hline 0.5 & & $27,764.25^{\mathrm{b}, \mathrm{w}}$ & $27,659.03^{\mathrm{b}, \mathrm{w}}$ & & & \\
\hline 1.5 & $27,679.23^{\mathrm{w}}$ & & $27,662.31^{\mathrm{b}, \mathrm{w}}$ & $27,750.57^{\mathrm{w}}$ & $27,652.12^{\mathrm{b}, \mathrm{w}}$ & \\
\hline 2.5 & $27,689.19^{\mathrm{w}}$ & $27,773.50^{\mathrm{b}}$ & $27,665.534$ & $27,748.18^{\mathrm{b}, \mathrm{w}}$ & $27,648.59^{\mathrm{b}, \mathrm{w}}$ & $27,730.01^{\mathrm{w}}$ \\
\hline 3.5 & $27,699.12^{\mathrm{b}, \mathrm{w}}$ & $27,778.655$ & $27,668.662$ & $27,746.16^{\mathrm{b}}$ & $27,644.95^{\mathrm{b}}$ & $27,720.78^{\mathrm{b}, \mathrm{w}}$ \\
\hline 4.5 & $27,708.97^{\mathrm{b}}$ & $27,784.20^{\mathrm{b}}$ & $27,671.731$ & $27,744.44^{\mathrm{b}}$ & $27,641.21^{\mathrm{b}}$ & $27,711.92^{\mathrm{b}}$ \\
\hline 5.5 & $27,718.743$ & $27,790.073$ & $27,674.748$ & $27,743.19^{\mathrm{b}}$ & $27,637.47^{\mathrm{b}}$ & $27,703.420$ \\
\hline 6.5 & $27,728.51^{\mathrm{b}}$ & $27,796.258$ & $27,677.735$ & $27,742.251$ & $27,633.66^{\mathrm{b}}$ & $27,695.361$ \\
\hline 7.5 & $27,738.225$ & $27,802.746$ & $27,680.690$ & $27,741.641$ & $27,629.861$ & $27,687.64^{\mathrm{b}}$ \\
\hline 8.5 & $27,747.94^{\mathrm{b}}$ & $27,809.549$ & $27,683.656$ & $27,741.37^{\mathrm{b}}$ & $27,626.014$ & $27,680.305$ \\
\hline 9.5 & $27,757.69^{\mathrm{b}}$ & $27,816.588$ & $27,686.624$ & $27,741.42^{\mathrm{b}}$ & $27,622.244$ & $27,673.310$ \\
\hline 10.5 & $27,767.412$ & $27,823.919$ & $27,689.622$ & $27,741.799$ & $27,618.461$ & $27,666.667$ \\
\hline 11.5 & $27,777.172$ & $27,831.469$ & $27,692.666$ & $27,742.421$ & $27,614.77^{\mathrm{b}}$ & $27,660.370$ \\
\hline 12.5 & $27,786.987$ & $27,839.26^{\mathrm{b}}$ & $27,695.764$ & $27,743.354$ & $27,611.135$ & 27654.394 \\
\hline 13.5 & $27,796.834$ & $27,847.32^{\mathrm{b}}$ & $27,698.938$ & $27,744.57^{\mathrm{b}}$ & $27,607.615$ & $27,648.75^{\mathrm{b}}$ \\
\hline 14.5 & $27,806.761$ & $27,855.579$ & $27,702.191$ & $27,746.04^{\mathrm{b}}$ & $27,604.219$ & $27,643.397$ \\
\hline 15.5 & $27,816.738$ & $27,864.042$ & $27,705.551$ & $27,747.771$ & $27,600.911$ & $27,638.371$ \\
\hline 16.5 & $27,826.800$ & $27,872.729$ & $27,709.01^{\mathrm{b}}$ & $27,749.76^{\mathrm{b}}$ & $27,597.766$ & $27,633.66^{\mathrm{b}}$ \\
\hline 17.5 & $27,836.92^{\mathrm{b}}$ & $27,881.599$ & $27,712.624$ & $27,752.036$ & $27,594.778$ & $27,629.263$ \\
\hline 18.5 & $27,847.14^{\mathrm{b}}$ & $27,890.681$ & $27,716.332$ & $27,754.556$ & $27,591.92^{\mathrm{b}}$ & $27,625.164$ \\
\hline 19.5 & $27,857.505$ & $27,899.96^{\mathrm{b}}$ & $27,720.194$ & $27,757.332$ & $27,589.331$ & $27,621.407$ \\
\hline 20.5 & $27,867.94^{\mathrm{b}}$ & $27,909.462$ & $27,724.218$ & $27,760.371$ & $27,586.893$ & $27,617.93^{\mathrm{b}}$ \\
\hline 21.5 & $27,878.485$ & $27,919.178$ & $27,728.41^{\mathrm{b}}$ & $27,763.663$ & $27,584.705$ & $27,614.83^{\mathrm{b}}$ \\
\hline 22.5 & $27,889.137$ & $27,929.063$ & $27,732.775$ & $27,767.227$ & $27,582.69^{\mathrm{b}}$ & $27,611.991$ \\
\hline 23.5 & $27,899.96^{\mathrm{b}}$ & $27,939.14^{\mathrm{w}}$ & $27,737.313$ & $27,771.05^{\mathrm{b}}$ & $27,580.953$ & $27,609.578$ \\
\hline 24.5 & $27,910.940$ & $27,949.51^{\mathrm{w}}$ & $27,742.08^{\mathrm{b}}$ & $27,775.18^{\mathrm{b}}$ & $27,579.492$ & \\
\hline 25.5 & $27,922.041$ & $27,959.99^{\mathrm{w}}$ & $27,747.042$ & $27,779.569$ & $27,578.286$ & \\
\hline 26.5 & $27,933.290$ & $27,970.78^{\mathrm{w}}$ & $27,752.247$ & $27,784.29^{\mathrm{b}}$ & $27,577.39^{\mathrm{b}}$ & \\
\hline 27.5 & $27,944.73^{\mathrm{b}}$ & & $27,757.69^{\mathrm{b}}$ & $27,789.251$ & $27,576.77^{\mathrm{b}}$ & \\
\hline 28.5 & $27,956.386$ & & $27,763.406$ & $27,794.56^{\mathrm{b}}$ & $27,576.49^{\mathrm{b}}$ & \\
\hline 29.5 & $27,968.215$ & & $27,769.367$ & $27,800.26^{\mathrm{b}}$ & $27,576.57^{\mathrm{b}}$ & \\
\hline 30.5 & $27,980.221$ & & $27,775.604$ & $27,806.23^{\mathrm{b}}$ & $27,577.00^{\mathrm{b}}$ & \\
\hline 31.5 & $27,992.55^{\mathrm{w}}$ & & $27,782.21^{\mathrm{b}}$ & $27,812.56^{\mathrm{b}}$ & $27,577.78^{\mathrm{b}}$ & \\
\hline 32.5 & $28,005.04^{\mathrm{w}}$ & & $27,789.11^{\mathrm{b}, \mathrm{w}}$ & $27,819.26^{\mathrm{b}}$ & $27,578.99^{\mathrm{b}}$ & \\
\hline 33.5 & $28,017.80^{\mathrm{w}}$ & & $27,796.31^{\mathrm{b}, \mathrm{w}}$ & $27,826.418$ & $27,580.64^{\mathrm{b}}$ & \\
\hline 34.5 & & & $27,803.93^{\mathrm{b}, \mathrm{w}}$ & $27,833.981$ & $27,582.76^{\mathrm{b}, \mathrm{w}}$ & \\
\hline 35.5 & & & & & $27,585.30^{\mathrm{w}}$ & \\
\hline$J$ & $R_{12 f f}$ & $R_{21 e e}$ & $Q_{12 e f}$ & $Q_{21 f e}$ & $P_{12 f f}$ & $P_{21 e e}$ \\
\hline 0.5 & $27,662.42$ & & $27,652.22$ & & & \\
\hline 1.5 & $27,665.60$ & $27,782.31$ & $27,648.68$ & $27,764.22$ & $27,638.52$ & \\
\hline 2.5 & $27,668.77$ & $27,793.98$ & $27,645.03$ & & $27,628.18$ & $27,750.46$ \\
\hline 3.5 & $27,671.86$ & $27,805.93$ & $27,641.36$ & $27,773.42$ & $27,617.64$ & $27,748.05$ \\
\hline 4.5 & $27,674.94$ & $27,818.31$ & $27,637.63$ & $27,778.52$ & $27,607.18$ & $27,746.00$ \\
\hline 5.5 & $27,677.92$ & $27,830.95$ & $27,633.86$ & $27,784.03$ & $27,596.61$ & $27,744.32$ \\
\hline 6.5 & $27,680.89$ & $27,843.84$ & $27,630.07$ & $27,789.87$ & $27,586.09$ & $27,742.97$ \\
\hline 7.5 & $27,683.93$ & $27,857.08$ & $27,626.28$ & $27,796.03$ & $27,575.48$ & $27,742.01$ \\
\hline 8.5 & $27,686.94$ & & $27,622.51$ & $27,802.50$ & $27,565.01$ & $27,741.37$ \\
\hline 9.5 & $27,689.97$ & $27,884.37$ & $27,618.76$ & $27,809.25$ & $27,554.46$ & $27,741.12$ \\
\hline 10.5 & $27,693.01$ & & $27,615.07$ & $27,816.25$ & $27,544.03$ & $27,741.12$ \\
\hline 11.5 & $27,696.13$ & $27,912.56$ & $27,611.52$ & $27,823.55$ & $27,533.68$ & $27,741.46$ \\
\hline 12.5 & & & $27,607.99$ & $27,831.10$ & & $27,742.08$ \\
\hline 13.5 & & $27,941.55$ & $27,604.64$ & $27,838.84$ & & $27,742.97$ \\
\hline 14.5 & & $27,956.30$ & $27,601.34$ & $27,846.89$ & & $27,744.12$ \\
\hline 15.5 & & & $27,598.21$ & & & \\
\hline 16.5 & & & $27,595.25$ & & & \\
\hline 17.5 & & & $27,592.51$ & & & \\
\hline 18.5 & & & $27,589.92$ & & & \\
\hline 19.5 & & & $27,587.45$ & & & \\
\hline 20.5 & & & $27,585.30$ & & & \\
\hline
\end{tabular}

${ }^{a}$ Absolute accuracy of the line frequency measurement amounts $0.005 \mathrm{~cm}^{-1}$ for the strongest lines and $0.01 \mathrm{~cm}^{-1}$ for the blended ("b") and/or weak ("w") ones as well as for all satellite branch lines. 
Table 2: Transition frequencies $\left(\right.$ in $\left.\mathrm{cm}^{-1}\right)$ of the $\mathrm{A}^{2} \Pi-\mathrm{X}^{2} \Sigma^{+}(1,1)$ band of $\mathrm{AlD}^{+}$. ${ }^{\mathrm{a}}$

\begin{tabular}{|c|c|c|c|c|c|c|}
\hline$J$ & $R_{11 e e}$ & $R_{22 f f}$ & $Q_{11 \mathrm{fe}}$ & $Q_{22 e f}$ & $P_{11 e e}$ & $P_{22 f f}$ \\
\hline 0.5 & $27,761.15^{\mathrm{b}, \mathrm{w}}$ & $27,856.22^{\mathrm{b}, \mathrm{w}}$ & & & & \\
\hline 1.5 & & $27,860.74^{\mathrm{b}, \mathrm{w}}$ & & & & \\
\hline 2.5 & $27,780.97^{\mathrm{b}, \mathrm{w}}$ & $27,865.63^{\mathrm{b}}$ & $27,757.81^{\mathrm{b}, \mathrm{w}}$ & $27,840.99^{w}$ & & $27,823.33^{w}$ \\
\hline 3.5 & $27,790.91^{\mathrm{w}}$ & & $27,761.15^{\mathrm{b}}$ & $27,839.33^{\mathrm{b}, \mathrm{w}}$ & $27,738.08^{\mathrm{b}, \mathrm{w}}$ & $27,814.69^{\mathrm{w}}$ \\
\hline 4.5 & $27,800.892$ & $27,876.855$ & $27,764.60^{\mathrm{b}}$ & $27,838.177$ & $27,734.90^{\mathrm{b}}$ & $27,806.485$ \\
\hline 5.5 & $27,810.913$ & $27,883.039$ & $27,767.963$ & $27,837.426$ & $27,731.70^{\mathrm{b}}$ & \\
\hline 6.5 & $27,821.034$ & $27,889.686$ & $27,771.436$ & $27,837.13^{\mathrm{b}}$ & $27,728.55^{\mathrm{b}}$ & $27,791.499$ \\
\hline 7.5 & $27,831.17^{\mathrm{b}}$ & $27,896.710$ & $27,774.989$ & $27,837.29^{\mathrm{b}}$ & $27,725.510$ & $27,784.701$ \\
\hline 8.5 & $27,841.439$ & $27,904.112$ & $27,778.655$ & $27,837.804$ & & $27,778.33^{\mathrm{b}}$ \\
\hline 9.5 & $27,851.788$ & $27,911.871$ & $27,782.414$ & $27,838.75^{\mathrm{b}}$ & $27,719.773$ & $27,772.392$ \\
\hline 10.5 & $27,862.275$ & $27,920.007$ & $27,786.300$ & $27,840.139$ & $27,717.083$ & $27,766.945$ \\
\hline 11.5 & $27,872.86^{\mathrm{b}}$ & $27,928.478$ & $27,790.346$ & $27,841.870$ & $27,714.563$ & $27,761.928$ \\
\hline 12.5 & $27,883.605$ & $27,937.290$ & $27,794.558$ & $27,844.030$ & $27,712.307$ & $27,757.33^{\mathrm{b}}$ \\
\hline 13.5 & $27,894.497$ & $27,946.446$ & $27,798.947$ & $27,846.554$ & $27,710.17^{\mathrm{b}}$ & $27,753.14^{\mathrm{b}}$ \\
\hline 14.5 & $27,905.560$ & $27,955.896$ & $27,803.536$ & $27,849.46^{\mathrm{b}}$ & $27,708.225$ & $27,749.389$ \\
\hline 15.5 & $27,916.796$ & $27,965.747$ & $27,808.327$ & $27,852.732$ & $27,706.564$ & \\
\hline 16.5 & $27,928.26^{\mathrm{b}}$ & $27,975.882$ & $27,813.364$ & $27,856.42^{\mathrm{b}}$ & $27,705.196$ & \\
\hline 17.5 & $27,939.874$ & $27,986.373$ & $27,818.656$ & $27,860.50^{\mathrm{b}}$ & $27,704.034$ & $27,740.790$ \\
\hline 18.5 & $27,951.746$ & $27,997.189$ & $27,824.191$ & $27,864.968$ & $27,703.22^{\mathrm{b}}$ & $27,738.79^{\mathrm{b}}$ \\
\hline 19.5 & $27,963.847$ & $28,008.380$ & $27,830.00^{\mathrm{b}}$ & & $27702.75^{\mathrm{b}}$ & $27,737.27^{\mathrm{b}}$ \\
\hline 20.5 & $27,976.224$ & $28,019.841$ & $27,836.153$ & $27,875.094$ & $27,702.56^{\mathrm{b}}$ & $27,736.18^{\mathrm{b}}$ \\
\hline 21.5 & $27,988.84^{\mathrm{b}, \mathrm{w}}$ & $28,031.714$ & $27,842.575$ & $27,880.800$ & $27,702.82^{\mathrm{b}}$ & $27,735.61^{\mathrm{b}}$ \\
\hline 22.5 & $28,001.74^{\mathrm{w}}$ & $28,043.95^{\mathrm{b}, \mathrm{w}}$ & $27,849.39^{\mathrm{b}}$ & $27,886.926$ & $27,703.38^{\mathrm{b}}$ & $27,735.55^{\mathrm{b}}$ \\
\hline 23.5 & & $28,056.56^{\mathrm{b}}$ & $27,856.50^{\mathrm{b}}$ & $27,893.512$ & $27,704.42^{\mathrm{b}}$ & $27,735.95^{\mathrm{b}}$ \\
\hline 24.5 & & & $27,864.04^{\mathrm{b}}$ & 27900.560 & $27,705.911$ & $27,736.890$ \\
\hline 25.5 & & & $27,871.928$ & $27,908 \cdot 10^{\mathrm{b}}$ & & $27,738.433$ \\
\hline 26.5 & & & $27,880.288$ & $27,916.139$ & & \\
\hline 27.5 & & & $27,889.137$ & $27,924.719$ & & \\
\hline 28.5 & & & $27,898.38^{\mathrm{b}}$ & $27,933.854$ & & \\
\hline 29.5 & & & $27,908.20^{\mathrm{b}}$ & $27,943.574$ & & \\
\hline 30.5 & & & $27,918.558$ & $27,953.922$ & & \\
\hline 31.5 & & & $27,929.475$ & $27,964.934$ & & \\
\hline 32.5 & & & $27,941.11^{\mathrm{w}}$ & $27,976.56^{\mathrm{b}}$ & & \\
\hline 33.5 & & & $27,953.38^{\mathrm{w}}$ & $27,988.93^{\mathrm{b}, \mathrm{w}}$ & & \\
\hline$J$ & $R_{12 f f}$ & $R_{21 e e}$ & $Q_{12 e f}$ & $Q_{21 f e}$ & $P_{12 f f}$ & $P_{21 e e}$ \\
\hline 1.5 & & & & $27,856.20$ & & \\
\hline 2.5 & & & $27,738.13$ & $27,860.68$ & $27,721.66$ & \\
\hline 3.5 & & $27,897.24$ & $27,735.02$ & $27,865.52$ & $27,711.85$ & $27,840.89$ \\
\hline 4.5 & $27,768.10$ & & $27,731.85$ & & & \\
\hline 5.5 & & $27,922.32$ & $27,728.76$ & $27,876.68$ & $27,692.34$ & $27,838.03$ \\
\hline 6.5 & & $27,935.49$ & $27,725.71$ & $27,882.90$ & $27,682.72$ & $27,837.25$ \\
\hline 7.5 & & $27,948.96$ & $27,722.84$ & $27,889.50$ & $27,673.26$ & $27,836.92$ \\
\hline 8.5 & $27,782.71$ & $27,962.81$ & & $27,896.50$ & $27,663.82$ & $27,837.04$ \\
\hline 9.5 & $27,786.58$ & $27,977.01$ & $27,717.41$ & $27,903.85$ & $27,654.57$ & $27,837.53$ \\
\hline 10.5 & $27,790.65$ & & $27,714.87$ & $27,911.56$ & $27,645.54$ & $27,838.46$ \\
\hline 11.5 & $27,794.90$ & $28,006.39$ & & $27,919.68$ & $27,636.66$ & $27,839.80$ \\
\hline 12.5 & $27,799.31$ & $28,021.48$ & $27,710.52$ & $27,928.12$ & $27,627.97$ & \\
\hline 13.5 & & $28,036.96$ & $27,708.61$ & $27,936.93$ & $27,619.62$ & \\
\hline 14.5 & & $28,052.69$ & & $27,946.01$ & $27,611.41$ & \\
\hline 15.5 & & & & $27,955.47$ & $27,603.55$ & \\
\hline 16.5 & & & & $27,965.29$ & $27,596.04$ & \\
\hline 17.5 & & & $27,703.73$ & $27,975.41$ & $27,588.86$ & \\
\hline 18.5 & & & & & $27,582.03$ & \\
\hline 19.5 & & & & & $27,575.56$ & \\
\hline
\end{tabular}




\section{Description of the spectra}

Two vibrational bands of the $\mathrm{AlD}^{+}$were observed in the $27,000-29,000$ $\mathrm{cm}^{-1}$ region. The bands with the strong heads at $27,713 \mathrm{~cm}^{-1}$ and 27,864 $\mathrm{cm}^{-1}$ have been recognized as $(0,0)$ and $(1,1)$ bands of the $\mathrm{A}^{2} \Pi-\mathrm{X}^{2} \Sigma^{+}$ system. We have no identified further $\Delta v=0$ bands, as in the expected region many lines with the low signal-to-noise ratio $(\mathrm{SNR} \approx 5)$ have been observed. Most of them belong to the $(0,0)$ and $(1,1)$ bands of $\mathrm{AlD}^{+}$and $\mathrm{AlH}^{+}$and other lines cannot be assigned to the desired $(2,2)$ and $(3,3)$ bands unambiguously.

The observed bands show a typical structure for the ${ }^{2} \Pi-{ }^{2} \Sigma^{+}$transition, when the upper state belongs to Hund's case $(a)$ and the lower state to case $(b)$. Twelve branches are expected, six each in the $\mathrm{A}^{2} \Pi_{1 / 2}-\mathrm{X}^{2} \Sigma^{+}$and $\mathrm{A}^{2} \Pi_{3 / 2}-\mathrm{X}^{2} \Sigma^{+}$subbands [23].

A part of the $\mathrm{AlD}^{+} \mathrm{A}-\mathrm{X}$ system spectrum, found between 27,650 and $29,740 \mathrm{~cm}^{-1}$, is shown in Fig. 1. In the same spectral region the bands of the $\mathrm{A}-\mathrm{X}$ system of $\mathrm{AlH}^{+}$occur with intensity of about $75 \%$ of the $\mathrm{AlD}^{+}$ bands. The identification of the $\mathrm{AlD}^{+}$lines was carried out by means of the information reported by us in our recent work [11] as well as on the basis current observations of the $\mathrm{AlH}^{+}$spectrum in the initial experiments (see Section 2). It should be stressed, that the $\mathrm{AlH}^{+}$transition frequencies for the good quality lines of the main branches obtained in two former observations are in agreement to within $\pm 0.002 \mathrm{~cm}^{-1}$.

The observed intensity of the $\mathrm{AlD}^{+}(1,1)$ band is about $50 \%$ of the intensity of the strongest $(0,0)$ band. We recognized rotational lines up to $J^{\prime}=36.5$ and $J^{\prime}=33.5$ in main branches of the $(0,0)$ and $(1,1)$ bands, respectively. The satellite branches were significantly weaker and can be followed up to the $J^{\prime}=20.5$ level in both the considered bands. The major impediment to the identification and measurements of any further lines was the presence of an analogous spectrum of the $\mathrm{A}^{2} \Pi-\mathrm{X}^{2} \Sigma^{+}$system in the studied region, deriving from the $\mathrm{AlH}^{+}$isotopologue. 


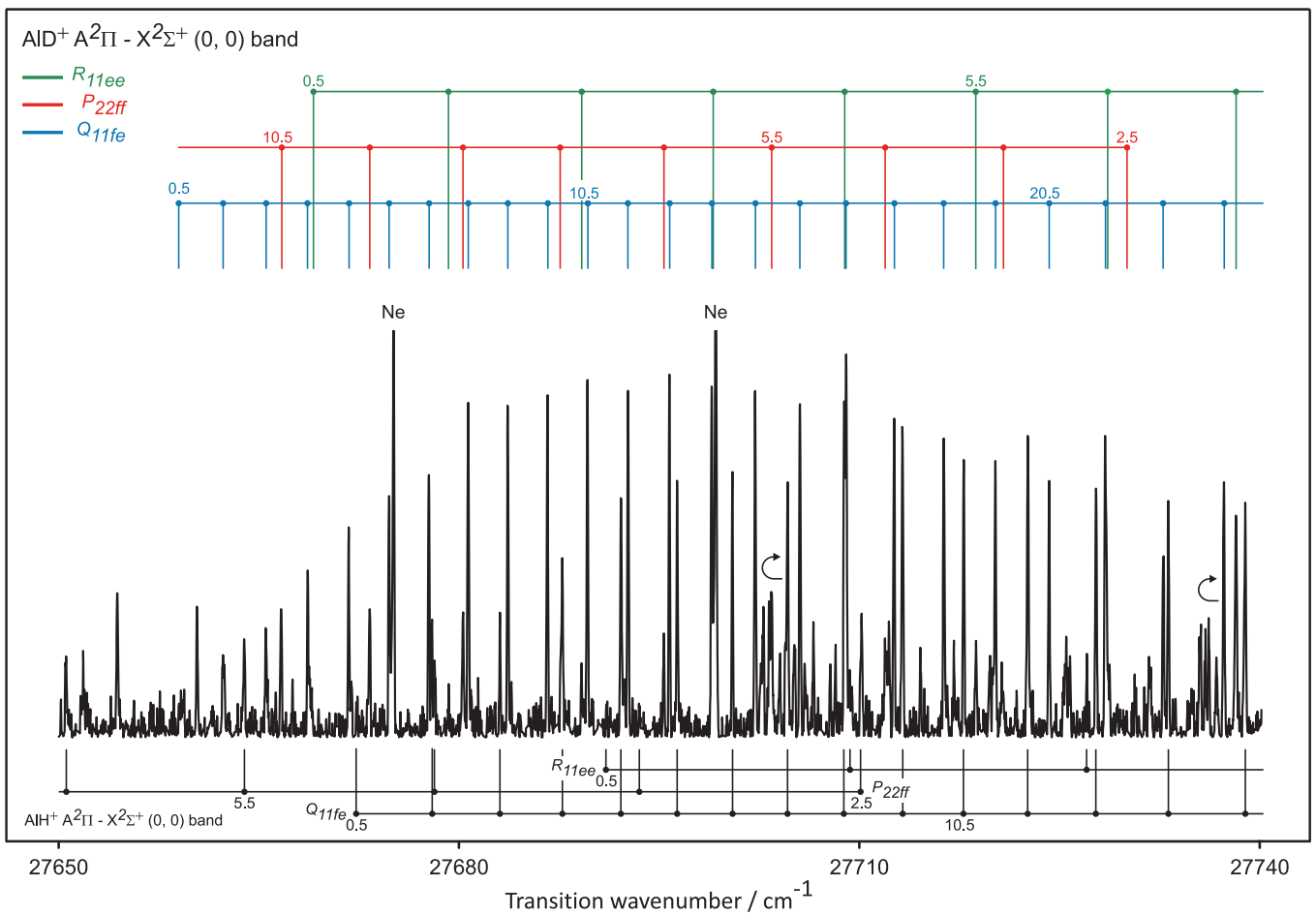

Figure 1: High-resolution VIS-FT emission spectrum of the $\mathrm{AlD}^{+} \mathrm{A}^{2} \Pi-\mathrm{X}^{2} \Sigma^{+}(0,0)$ band recorded with an instrumental resolution of $0.03 \mathrm{~cm}^{-1}$. The $\mathrm{SNR}$ was ca. $50: 1$. Only main $R_{11}, Q_{11}, P_{11}$ branch lines are interpreted. Lines of the $\mathrm{AlH}^{+} \mathrm{A}^{2} \Pi-\mathrm{X}^{2} \Sigma^{+}(0,0)$ band, occurring in the same spectral region, are marked at the bottom. Two characteristic features distinguished by turning back arrows are the $P_{11}$ and $P_{22}$ branch heads of the $\mathrm{AlD}^{+} \mathrm{A}^{2} \Pi-\mathrm{X}^{2} \Sigma^{+}(1,1)$ band at the $27,703 \mathrm{~cm}^{-1}$ and $27,735 \mathrm{~cm}^{-1}$, respectively. 


\section{Computational method}

$A b$ initio calculations on the ion were performed using a parallel version of the MOLPRO [24] (version 2010.1) suite of quantum chemistry codes. The calculations are based on a Hartree-Fock treatment of the ground electronic wavefunction $\left({ }^{2} \Sigma^{+}\right)$, the only molecular state that correlates to the lowest dissociation limit $\mathrm{Al}^{+}\left({ }^{1} \mathrm{~S}\right)+\mathrm{D}\left({ }^{2} \mathrm{~S}\right)$. As is normal for treating molecules with $\mathrm{C}_{\infty v}$ symmetry the Abelian point group $\mathrm{C}_{2 v}$ is used to describe the diatomic orbitals and molecular symmetry labels. To describe the atomic orbitals, one-electron Gaussian functions from the correlation consistent aug $-\mathrm{cc}-\mathrm{pV} 5 \mathrm{Z}$ basis set $[16,19]$ was used for both atoms.

The static electron correlation was calculated using the State-Averaged Complete Active Space Self-Consistent Field (SA-CASSCF) method [17]. The active space consisted of all the occupied valence orbitals of the aluminum atom plus the $1 s$ orbital from the deuterium atom. The $1 s$ orbital on the $\mathrm{Al}^{+}$atom is kept frozen while the $2 s 2 p$ orbitals are closed (kept doubly occupied in all configurations). In addition, $\mathrm{SA}-\mathrm{CASSCF}$ can be used to calculate the excited electronic states corresponding to the $\mathrm{Al}^{+}\left({ }^{3} \mathrm{P}\right)+\mathrm{D}\left({ }^{2} \mathrm{~S}\right)$ asymptote so a total of five electronic states are included $\left(2 \times{ }^{2} \Sigma^{+},{ }^{2} \Pi,{ }^{4} \Sigma^{+}\right.$, $\left.{ }^{4} \Pi\right)$. The accuracy of the potentials can be improved by including dynamic electron correlation, that was handled here by using the MRCI method [25]. This makes one and two electron excitations of all the configurations that make up the SA-CASSCF wavefunction. As the MOLPRO MRCI code is restricted to excitations of single or double electrons it is necessary to use the Davidson correction [26] to estimate the higher order contributions to the electronic energy.

The MOLPRO spin-orbit code [27] is used to compute the spin-orbit coupling matrix elements (including the relevant ladder operators) as well as the TDMs based on the MRCI wavefunctions. 


\section{Experimental results and discussion}

The results of Balfour and Lindgren [14], especially the reported negative values of the $p_{0,1}$ constants of the $\mathrm{A}^{2} \Pi$ state, have suggested some irregularities in the $\Lambda$-doubling of the first excited state of $\mathrm{AlD}^{+}$. Our preliminary analysis have confirmed these previous observations. Consequently, the observed levels of the $\mathrm{A}^{2} \Pi$ state has been represented by the rotational term values while for the more regular $\mathrm{X}^{2} \Sigma^{+}$state the usual molecular constants are used. However, we decided to provide effective values of the molecular constants for the $\mathrm{A}^{2} \Pi v=0,1$ level by fitting the current $(0,0)$ and $(1,1)$ bands data to a regular Hamiltonian (see Section 5.3).

\subsection{Molecular constants of the $X^{2} \Sigma^{+} v=0,1$ levels}

For the ground state constants determination we used the least-squares method proposed by Curl and Dane [28] and Watson [29]. This type of approach is an efficient means to separate molecular information concerning the lower $\mathrm{X}^{2} \Sigma^{+} v=0,1$, which are considered to be regular, from that which concerns the perturbed $\mathrm{A}^{2} \Pi v=0,1$ upper state. The $\mathrm{X}^{2} \Sigma^{+}$state was represented by the effective Hamiltonian proposed by Brown et al. [30] while the rotational terms of the $v=0,1$ levels of the $\mathrm{A}^{2} \Pi$ state were treated as independent parameters in the fit $[28,29]$. Direct matrix elements of the Hamiltonian for a ${ }^{2} \Sigma^{+}$state were given by Amiot et al. [31] and Douay et al. [32].

The fit of the $\mathrm{A}-\mathrm{X}(0,0)$ and $(1,1)$ bands has given satisfactory results with the acceptably low standard deviations of $0.012 \mathrm{~cm}^{-1}$ and $0.014 \mathrm{~cm}^{-1}$, respectively. It shows that there was no evidence of systematic trends in the residuals, indicating that all lines were adequately fitted.

Currently obtained $B_{0,1}$ and $\gamma_{0,1}$ constants (see Table 3 ) of the ground state confirm the previous results derived by Balfour and Lindgren [14]. A slight differences in the $D_{0,1}$ values arise from the influence of the $H_{0,1}$ constants which were included in our fit.

\subsection{Rotational term values of the $A^{2} \Pi v=0,1$ levels}

The experimental $\mathrm{A}^{2} \Pi v=0,1$ term values were derived by adding the measured line frequencies (see Table 1 and 2) to the appropriate $\mathrm{X}^{2} \Sigma^{+} v=$ 0,1 term values calculated from the $\mathrm{X}$ state constants determined above and collected in Table 3. For the $\mathrm{A}^{2} \Pi F_{1 e}, F_{1 f}, F_{2 e}$ and $F_{2 f}$ levels, at most three individual values for each $J$ number were calculated; the exact value 
Table 3: Experimental molecular constants $\left(\right.$ in $\mathrm{cm}^{-1}$ ) of the $\mathrm{X}^{2} \Sigma^{+}$state of $\mathrm{AlD}^{+}{ }^{\text {a }}$

\begin{tabular}{|llllll|}
\hline \multirow{2}{*}{ Constant } & \multicolumn{2}{l}{$\mathrm{X}^{2} \Sigma^{+} v=0$} & & & $\mathrm{X}^{2} \Sigma^{+} v=1$ \\
\cline { 2 - 3 } \cline { 5 - 6 } & $\begin{array}{l}\text { This } \\
\text { work }\end{array}$ & $\begin{array}{l}\text { Balfour } \\
\text { and Lindgren [14] }\end{array}$ & & Thork & $\begin{array}{l}\text { Balfour } \\
\text { and Lindgren [14] }\end{array}$ \\
\hline$B_{v}$ & $3.42867(11)$ & $3.4299(2)$ & & $3.29470(19)$ & $3.2957(3)$ \\
$D_{v} \times 10^{4}$ & $1.1994(20)$ & $1.237(2)$ & & $1.2789(58)$ & $1.342(3)$ \\
$H_{v} \times 10^{8}$ & $-0.211(10)$ & & & $-0.698(55)$ & \\
$\gamma_{v} \times 10^{2}$ & $2.910(29)$ & $2.91(6)$ & & $2.735(32)$ & $2.64(6)$ \\
\hline
\end{tabular}

${ }^{\text {a }}$ Numbers in parentheses represent a $1 \sigma$ error estimate.

depended on the number of the main and/or satellite branches observed in the $\mathrm{A}-\mathrm{X}(0,0)$ and $(1,1)$ bands. Next, the single weighted average values were calculated. The individual values were weighted on the basis the estimated accuracy of the measured transition frequencies of the rotational lines (see Section 5.3). The estimated global accuracy of the term values determined in this way is about $0.03 \mathrm{~cm}^{-1}$. The final results are collected in Table 4 .

Our program returns rotational term values for the upper $A^{2} \Pi$ state, relative to the lowest term of the appropriate vibrational level of the lower $\mathrm{X}^{2} \Sigma^{+}$state. The absolute position of the $\mathrm{A}^{2} \Pi v=1$ terms, relative to the $\mathrm{X}^{2} \Sigma^{+} v=0 J=0.5 F_{1 e}$, can be calculated by adding the $G(1)-G(0)$ difference for the ground state. Currently, only $a b$ initio value for this is known and equals $1664.84 \mathrm{~cm}^{-1}$ (see Table 6). The former value can be verified by the future theoretical results or by the experimental investigations when the $(1,0)$ band of the $\mathrm{A}-\mathrm{X}$ system will be observed.

The rotational term values of Table 4, have been used to the graphical presentation of the $\Lambda$-doubling observed in the $\mathrm{A}^{2} \Pi v=0,1$ levels (see Fig. 5(a) in Section 7). 
Table 4: Experimental values of the rotational term $\left(\right.$ in $\mathrm{cm}^{-1}$ ) of the $\mathrm{A}^{2} \Pi v=0,1$ levels of $\mathrm{AlD}^{+} \cdot \mathrm{a}$

\begin{tabular}{|c|c|c|c|c|c|c|c|c|}
\hline \multirow[b]{2}{*}{$J$} & \multicolumn{4}{|c|}{$\mathrm{A}^{2} \Pi v=0^{\mathrm{b}}$} & \multicolumn{4}{|c|}{$\mathrm{A}^{2} \Pi v=1^{\mathrm{c}}$} \\
\hline & $F_{1 e}$ & $F_{1 f}$ & $F_{2 e}$ & $F_{2 f}$ & $F_{1 e}$ & $F_{1 f}$ & $F_{2 e}$ & $F_{2 f}$ \\
\hline 0.5 & $27,659.03$ & $27,659.04$ & & & & & & \\
\hline 1.5 & $27,669.19$ & $27,669.22$ & $27,771.08$ & $27,771.08$ & & $27,761.12$ & & $27,862.79$ \\
\hline 2.5 & $27,686.11$ & $27,686.12$ & $27,789.22$ & $27,789.23$ & $27,777.62$ & $27,777.61$ & $27,880.45$ & $27,880.47$ \\
\hline 3.5 & $27,709.80$ & $27,709.84$ & $27,814.59$ & $27,814.58$ & $27,800.78$ & $27,800.77$ & $27,905.10$ & $27,905.11$ \\
\hline 4.5 & $27,740.29$ & $27,740.31$ & $27,847.11$ & $27,847.11$ & $27,830.48$ & $27,830.46$ & $27,936.82$ & \\
\hline 5.5 & $27,777.55$ & $27,777.58$ & $27,886.88$ & $27,886.87$ & $27,866.80$ & $27,866.75$ & $27,975.48$ & $27,975.49$ \\
\hline 6.5 & $27,821.58$ & $27,821.61$ & $27,933.76$ & $27,933.76$ & $27,909.71$ & $27,909.67$ & $28,021.12$ & $28,021.12$ \\
\hline 7.5 & $27,872.38$ & $27,872.43$ & $27,987.74$ & $27,987.77$ & $27,959.27$ & $27,959.18$ & $28,073.72$ & $28,073.68$ \\
\hline 8.5 & $27,929.97$ & $27,930.02$ & $28,048.83$ & $28,048.85$ & $28,015.37$ & $28,015.31$ & $28,133.15$ & $28,133.13$ \\
\hline 9.5 & $27,994.30$ & $27,994.37$ & $28,116.96$ & $28,116.99$ & $28,078.10$ & $28,078.03$ & $28,199.47$ & $28,199.45$ \\
\hline 10.5 & $28,065.41$ & $28,065.47$ & $28,192.11$ & $28,192.12$ & $28,147.38$ & $28,147.30$ & $28,272.62$ & $28,272.58$ \\
\hline 11.5 & $28,143.26$ & $28,143.32$ & $28,274.18$ & $28,274.22$ & $28,223.28$ & $28,223.15$ & $28,352.53$ & $28,352.50$ \\
\hline 12.5 & $28,227.83$ & $28,227.88$ & $28,363.19$ & $28,363.23$ & $28,305.70$ & $28,305.56$ & $28,439.20$ & $28,439.13$ \\
\hline 13.5 & $28,319.12$ & $28,319.16$ & $28,459.06$ & $28,459.10$ & $28,394.60$ & $28,394.49$ & $28,532.53$ & $28,532.45$ \\
\hline 14.5 & $28,417.06$ & $28,417.11$ & $28,561.76$ & $28,561.81$ & $28,490.04$ & $28,489.91$ & $28,632.51$ & $28,632.42$ \\
\hline 15.5 & $28,521.68$ & $28,521.71$ & $28,671.21$ & $28,671.28$ & $28,591.95$ & $28,591.80$ & $28,739.06$ & $28,738.95$ \\
\hline 16.5 & $28,632.90$ & $28,632.92$ & $28,787.38$ & $28,787.48$ & $28,700.27$ & $28,700.14$ & $28,852.18$ & $28,852.08$ \\
\hline 17.5 & $28,750.71$ & $28,750.75$ & $28,910.25$ & $28,910.34$ & $28,815.03$ & $28,814.90$ & $28,971.79$ & $28,971.65$ \\
\hline 18.5 & $28,875.07$ & $28,875.09$ & $29,039.72$ & $29,039.82$ & $28,936.13$ & $28,935.99$ & $29,097.84$ & $29,097.67$ \\
\hline 19.5 & $29,005.90$ & $29,005.93$ & $29,175.75$ & $29,175.85$ & $29,063.54$ & $29,063.41$ & & $29,230.05$ \\
\hline 20.5 & $29,143.24$ & $29,143.24$ & $29,318.29$ & $29,318.41$ & $29,197.26$ & $29,197.13$ & $29,368.96$ & $29,368.78$ \\
\hline 21.5 & $29,286.94$ & $29,286.95$ & $29,467.25$ & $29,467.37$ & $29,337.19$ & $29,337.04$ & $29,513.96$ & $29,513.74$ \\
\hline 22.5 & $29,437.02$ & $29,437.02$ & $29,622.60$ & $29,622.77$ & $29,483.29$ & $29,483.16$ & $29,665.14$ & $29,664.88$ \\
\hline 23.5 & $29,593.40$ & $29,593.37$ & $29,784.25$ & $29,784.44$ & $29,635.52$ & $29,635.36$ & $29,822.45$ & $29,822.16$ \\
\hline 24.5 & $29,756.03$ & $29,755.99$ & $29,952.19$ & $29,952.34$ & & $29,793.65$ & $29,985.82$ & $29,985.50$ \\
\hline 25.5 & $29,924.85$ & $29,924.79$ & $30,126.26$ & $30,126.51$ & & $29,957.88$ & $30,155.18$ & \\
\hline 26.5 & $30,099.78$ & $30,099.71$ & $30,306.49$ & $30,306.69$ & & $30,128.09$ & $30,330.45$ & \\
\hline 27.5 & $30,280.76$ & $30,280.69$ & $30,492.70$ & $30,492.99$ & & $30,304.20$ & $30,511.56$ & \\
\hline 28.5 & $30,467.75$ & $30,467.68$ & $30,684.89$ & & & $30,486.01$ & $30,698.44$ & \\
\hline 29.5 & $30,660.66$ & $30,660.56$ & $30,883.04$ & & & $30,673.60$ & $30,891.00$ & \\
\hline 30.5 & $30,859.38$ & $30,859.27$ & $31,086.91$ & & & $30,866.82$ & $31,089.17$ & \\
\hline 31.5 & $31,063.89$ & $31,063.80$ & $31,296.52$ & & & $31,065.58$ & $31,292.86$ & \\
\hline 32.5 & $31,274.12$ & $31,274.01$ & $31,511.75$ & & & $31,269.93$ & $31,501.90$ & \\
\hline 33.5 & $31,489.95$ & $31,489.78$ & $31,732.62$ & & & $31,479.64$ & $31,716.28$ & \\
\hline 34.5 & $31,711.28$ & $31,711.13$ & $31,958.93$ & & & & & \\
\hline
\end{tabular}

\subsection{Molecular constants of the $A^{2} \Pi v=0,1$ levels}

As the observed $J$-dependence of the $\Lambda$-doubling of the $\mathrm{A}^{2} \Pi$ state is smooth (see Fig. 5(a)), we decided to fit the observed data to a regular Hamiltonian to get an effective parameters of the $\mathrm{A}^{2} \Pi$ state. We used the PGOPHER software [33] with a ${ }^{2} \Pi$ state matrix elements definied by Amiot et al. [31] and Douay et al. [32]. The rotational structure of the ground state was fixed to the constants obtained in first step and collected in Table 3 (see Section 5.1).

The input set of the data contains 484 transition frequencies for both $(0,0)$ and $(1,1)$ bands of the $\mathrm{A}^{2} \Pi-\mathrm{X}^{2} \Sigma^{+}$transition of $\mathrm{AlD}^{+}$. Each line-frequency have been individually weighted, according its accuracy: 1 is assigned to strong, isolated lines and 0.5, 0.25, 0.15 to weak and/or blended transitions. 
The root-mean-square error (rmse) of unweighted transition-frequency residuals is $0.015 \mathrm{~cm}^{-1}$ and is dominated by the uncertainties of the weak and blended satellite lines.

The final set of $\mathrm{A}^{2} \Pi v=0,1$ molecular constants is listed in Table 5 while the obtained band origin values are $27,706.1142(20) \mathrm{cm}^{-1}$ and $27,798.3084(31)$ $\mathrm{cm}^{-1}$ for the $(0,0)$ and $(1,1)$ band, respectively. To reduce the correlation between $A_{D, v}$ and $\gamma_{v}$ parameters of the $\mathrm{A}^{2} \Pi$ state [35] the $A_{D, v=0,1}$ constants were fixed to the same value calculated from the formula provided by Veseth [34]:

$$
A_{D}=\frac{2\left(A_{v+1}-A_{v}\right) D_{v=0}}{B_{v}-B_{v+1}+6 B_{e}^{2} / \omega_{e}} .
$$

It gives $A_{D, 0}=-0.663 \times 10^{-3} \mathrm{~cm}^{-1}$, on the basis $B_{0,1}, D_{0}, A_{0,1}$ constants from [14] and $B_{e}, \omega_{e}$ equilibrium parameters recalculated from $\mathrm{AlH}^{+}$ data [36]. The above $A_{D, v=0,1}$ values can be compared with the experiential results of Balfour and Lindgren [14] $A_{D, 0}=-9.3(5) \times 10^{-3} \mathrm{~cm}^{-1}$ and $A_{D, 1}=-12(1) \times 10^{-3} \mathrm{~cm}^{-1}$, obtained by authors from the fit with $\gamma_{0,1}$ equal zero. The analogous fit of current data results in $A_{D, v}$ constant values as follows: $A_{D, 0}=-0.647(11) \times 10^{-3} \mathrm{~cm}^{-1}$ and $A_{D, 1}=-1.636(19) \times 10^{-3} \mathrm{~cm}^{-1}$.

The present excited state constants are compatible but more accurate than results of the previous study [14]. In addition, we obtained a more complete set of band constants for the $\mathrm{A}^{2} \Pi v=0,1$ levels, including new values of the $p_{0,1}$ and $q_{0,1} \Lambda$-doubling parameters. The former values have to be treated with a great care as they are only effective fitting parameters and cannot be used to understand the sources of the observed anomalous $\Lambda$-doubling in the $\mathrm{A}^{2} \Pi$ state.

Both $p_{0}$ and $p_{1}$ constants, but especially $p_{0}$, are quite different from those reported by Balfour and Lindgren [14]. From the pure precession theory [37, 38 ] we can estimate the sign and approximate value of the $\Lambda$-doubling constants for the $\mathrm{A}^{2} \Pi$ state of $\mathrm{AlD}^{+}$. We have assumed the separate interaction between the $\mathrm{A}^{2} \Pi$ state and a nearby ${ }^{2} \Sigma^{+}$states (see Fig. 2): $\mathrm{X}^{2} \Sigma^{+}$(ground state) and $\mathrm{B}^{2} \Sigma^{+}\left(\right.$at $\left.31,400 \mathrm{~cm}^{-1}\right)$. For estimation we used $l=0$ with present experimental $A_{0}, B_{0}$ constants and $E^{\Pi}-E^{\Sigma^{+}}$distances calculated from theoretical $T_{0}^{\mathrm{A}}$ and $T_{0}^{\mathrm{B}}$ values of Table 6 .

In the first case, the $p_{v}$ and $q_{v}$ should both be positive with values about of $+0.03 \mathrm{~cm}^{-1}$ and $+0.0009 \mathrm{~cm}^{-1}$. In the second case, both are expected to be negative and equal ca. $-0.2 \mathrm{~cm}^{-1}$ and $-0.007 \mathrm{~cm}^{-1}$, respectively. However, the $p_{v}$ and $q_{v}$ constants are actually observed to be positive for 
Table 5: Effective molecular constants $\left(\right.$ in $\mathrm{cm}^{-1}$ ) of the $\mathrm{A}^{2} \Pi$ state of $\mathrm{AlD}^{+}$.

\begin{tabular}{|llllll|}
\hline \multirow{2}{*}{ Constant } & $\mathrm{A}^{2} \Pi v=0$ & & $\mathrm{~A}^{2} \Pi v=1$ & \\
\cline { 2 - 3 } \cline { 5 - 6 } & $\begin{array}{l}\text { This } \\
\text { work }\end{array}$ & $\begin{array}{l}\text { Balfour } \\
\text { and Lindgren }[14]\end{array}$ & & $\begin{array}{l}\text { This } \\
\text { work }\end{array}$ & $\begin{array}{l}\text { Balfour } \\
\text { and Lindgren [14] }\end{array}$ \\
\hline$B_{v}$ & $3.506760(19)$ & $3.50507(5)$ & & $3.415792(32)$ & $3.4155(2)$ \\
$D_{v} \times 10^{4}$ & $1.12375(46)$ & $1.1035(4)$ & & $1.10772(81)$ & $1.120(2)$ \\
$H_{v} \times 10^{8}$ & $0.1103(29)$ & & $-0.0614(54)$ & \\
$A_{v}$ & $108.1884(33)$ & $108.21(2)$ & & $107.8042(55)$ & $107.76(3)$ \\
$A_{D, v} \times 10^{3}$ & $-0.667^{\mathrm{b}}$ & $-9.3(5)$ & & $-0.667^{\mathrm{b}}$ & $-12(1)$ \\
$\gamma_{v} \times 10^{3}$ & $-1.62(40)$ & & $8.63(72)$ & \\
$\gamma_{D, v} \times 10^{6}$ & $2.03(56)$ & & $10.4(11)$ & \\
$p_{v} \times 10^{3}$ & $6.88(25)$ & $-1.1(9)$ & & $-10.48(49)$ & $-5(2)$ \\
$p_{D, v} \times 10^{5}$ & $-0.220(54)$ & & $-1.22(13)$ & \\
$q_{v} \times 10^{4}$ & $2.715(75)$ & & $-3.585(93)$ & \\
\hline
\end{tabular}

${ }^{\text {a }}$ Numbers in parentheses represent a $1 \sigma$ error estimate.

${ }^{\mathrm{b}}$ Fixed at computed value (see text).

the $v=0$ and negative for $v=1$ (see Table 5). This discrepancy reveals that the pure precession model that we assumed, between $\mathrm{A} \sim \mathrm{X}$ or $\mathrm{A} \sim \mathrm{B}$ states, does not describe the observed $\Lambda$-doubling in the $\mathrm{A}^{2} \Pi$ state correctly. Presumably, the $\mathrm{A}^{2} \Pi$ state interacts with the $\mathrm{X}^{2} \Sigma^{+}$and $\mathrm{B}^{2} \Sigma^{+}$states in more complicated way and/or the other ${ }^{2} \Sigma^{+/-}$states can substantially contribute to the observed phenomenon. 


\section{Ab initio results and discussion}

The calculated electronic states correlating to the lowest atomic asymptotes of the aluminum ion are presented in Fig 2. The ground state potential is quite shallow with a dissociation energy $\mathrm{D}_{e}$ of $7275 \mathrm{~cm}^{-1}$. As the zero-point energy is large on account of being a deuteride $\left(608 \mathrm{~cm}^{-1}\right)$, the $\mathrm{D}_{0}$ dissociation energy is significantly smaller $\left(6667 \mathrm{~cm}^{-1}\right)$. The calculations suggest that even the ${ }^{4} \Sigma^{+}$state, though essentially a repulsive electronic potential, possesses an equilibrium bond length $\left(\mathrm{r}_{e}=4.337 \AA, \mathrm{D}_{e}=120 \mathrm{~cm}^{-1}\right)$ though it does not support a bound level.

(a)

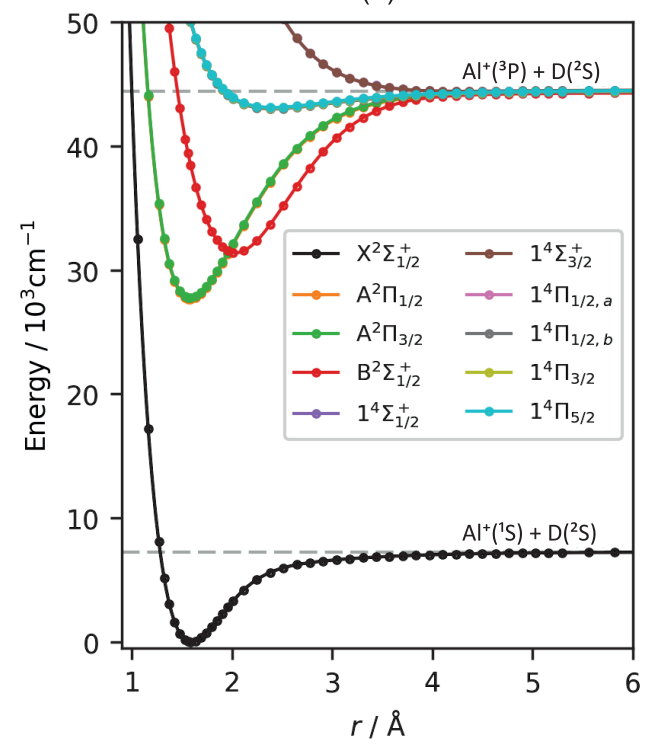

(b)

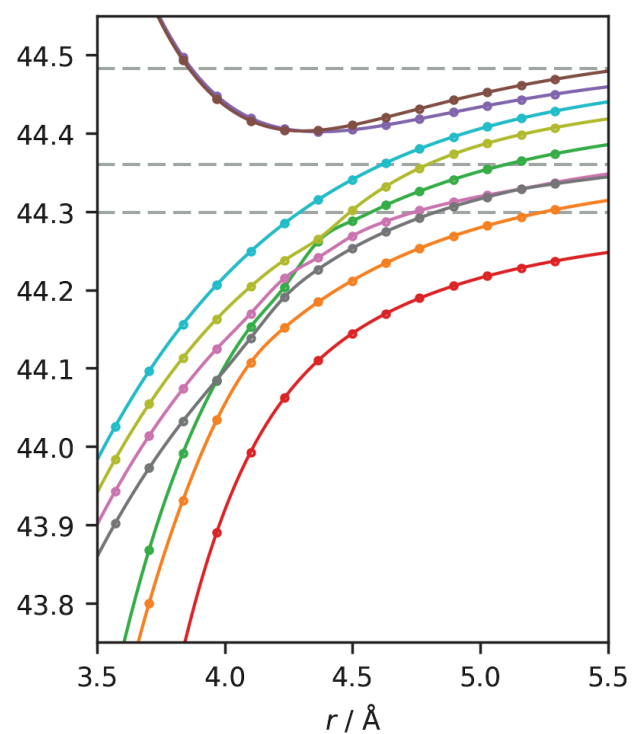

Figure 2: Ab initio MRCI+Q (with Davidson correction) results for $\mathrm{AlD}^{+}$calculated using the AV5Z basis set: (a) the potential energy curves out to $6 \AA$, where the spin-orbit separation begins to match the values of the $\mathrm{Al}^{+}\left({ }^{3} \mathrm{P}\right)$ ion, (b) a close up of the long-range region close to the excited $\mathrm{Al}^{+}$asymptote to reveal the interaction between the individual molecular spin-orbit states. Note all potentials are bound though neither ${ }^{4} \Sigma^{+}$spin-orbit component can support a rovibrational level.

The calculated dipoles, both permanent and transition varieties, are shown in Fig. 3, while the spin-orbit coupling matrix (SO-matrix) elements are presented in Fig. 4. The latter are consistent at long range with the results of Nguyen et al. [3] though at shorter range they are generally greater in magnitude. 
(a)

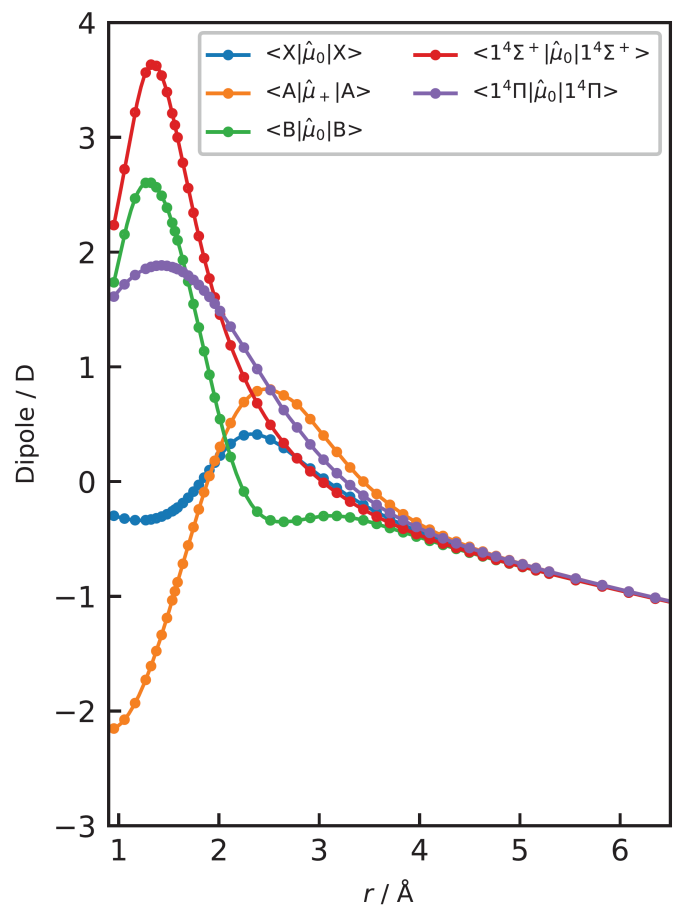

(b)

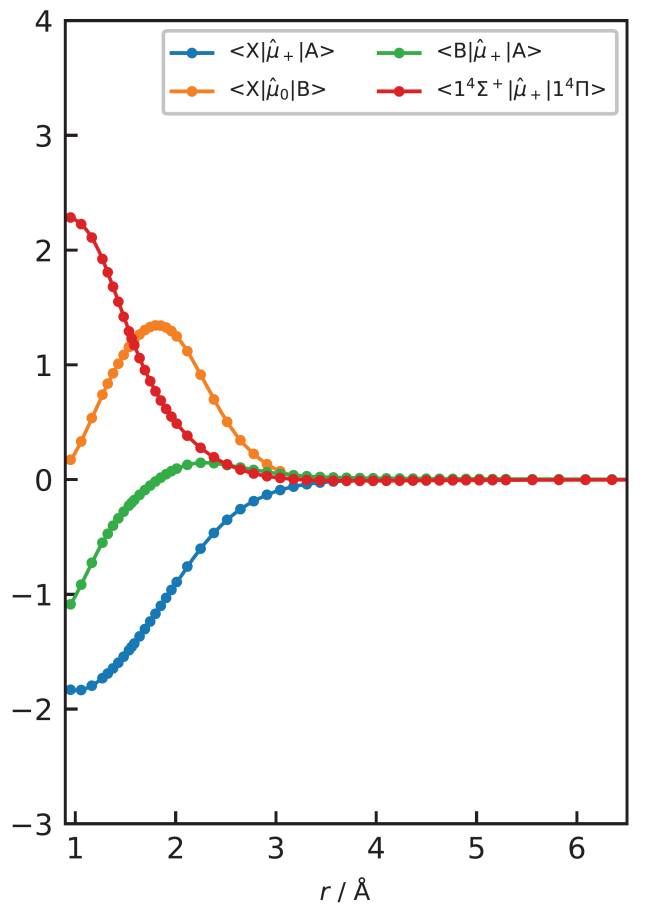

Figure 3: Ab initio dipole moments calculated using the AV5Z basis set and based on the MRCI wavefunctions (using the spin-orbit routine [27] in MOLPRO.) In (a) are the DMFs and (b) the TDMs, the latter are all zero at long range because of the $\Delta \mathrm{S}=0$ and Laporte selection rules.

The molecular rovibrational levels in each electronic state can be calculated using the DUO code [39]. MOLPRO conducts ab initio calculations in the $C_{2 v}$ point group symmetry, while DUO handles explicitly $C_{\infty v}$ symmetry states. Therefore, a series of conversions [40] are necessary to prepare the MOLPRO output prior to use: 


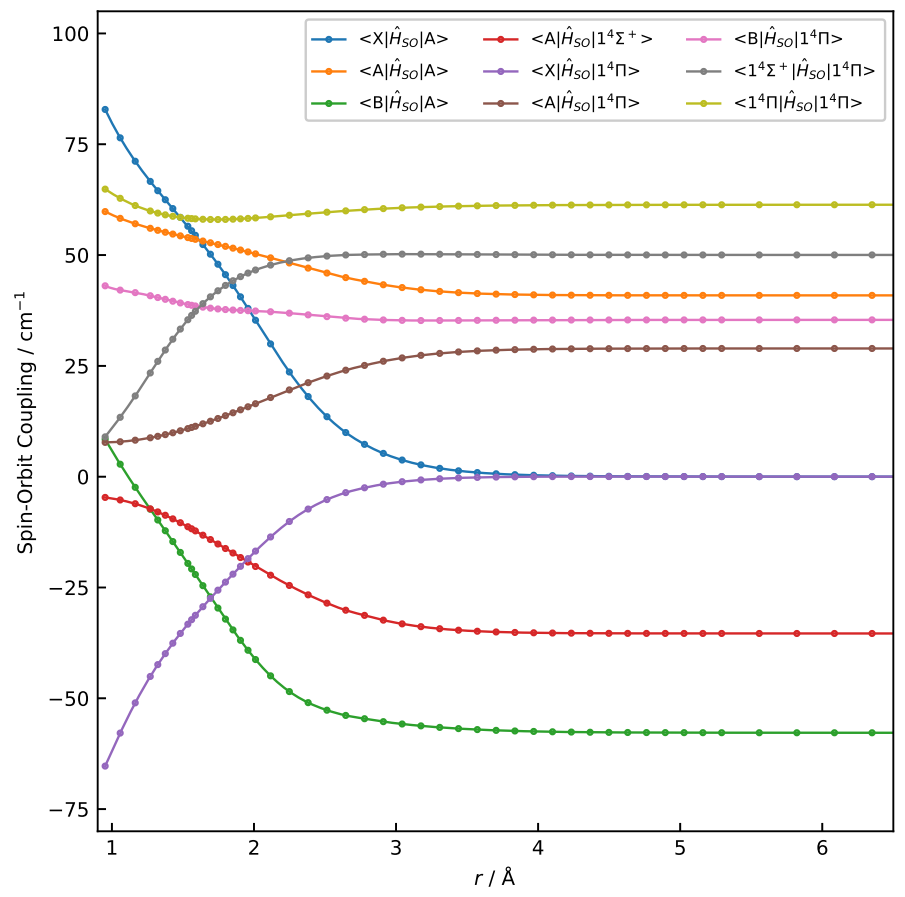

Figure 4: The spin-orbit matrix elements as a function of internuclear separation calculated at the MRCI level [27] using the AV5Z basis set. $\left\langle X\left|H_{S O}\right| A\right\rangle \equiv$ $\left\langle X^{2} \Sigma^{+}, 0,-\frac{1}{2}\left|\hat{H}_{S O}\right| A^{2} \Pi,-1,+\frac{1}{2}\right\rangle$ etc (see text).

$$
\begin{aligned}
& { }^{2} \Sigma^{+} \text {states } \\
& \left|n \Sigma, 0, \pm \frac{1}{2}\right\rangle=\left|n A_{1}, \pm \frac{1}{2}\right\rangle \\
& { }^{2} \Pi \text { states } \\
& \left|n \Pi, \pm 1, \pm \frac{1}{2}\right\rangle=\mp\left|n B_{1}, \pm \frac{1}{2}\right\rangle-i\left|n B_{2}, \pm \frac{1}{2}\right\rangle \\
& \text { Dipole } \\
& \hat{\mu}_{0}=\hat{\mu}_{z} \\
& \hat{\mu}_{ \pm}=\mp \frac{1}{\sqrt{2}}\left(\hat{\mu}_{x} \pm i \hat{\mu}_{y}\right) \\
& \text { Ladder } \\
& \hat{L}_{ \pm}=\hat{L}_{x} \pm i \hat{L}_{y} \\
& \text { Spin-Orbit } \\
& \hat{H}_{S O}=\hat{H}_{S O, x}+\hat{H}_{S O, y}+\hat{H}_{S O, z} \\
& S O_{\Sigma-\Pi} \quad\left\langle{ }^{2} \Sigma^{+}, 0,-\frac{1}{2}\left|\hat{H}_{S O}\right|^{2} \Pi,-1,+\frac{1}{2}\right\rangle= \\
& \frac{1}{\sqrt{2}}\left(\left\langle A_{1},-\frac{1}{2}\left|\hat{H}_{S O, y}\right| B_{1},+\frac{1}{2}\right\rangle-i\left\langle A_{1},-\frac{1}{2}\left|\hat{H}_{S O, x}\right| B_{2},+\frac{1}{2}\right\rangle\right) \\
& S O_{\Pi-\Pi} \quad\left\langle{ }^{2} \Pi,+1,+\frac{1}{2}\left|\hat{H}_{S O}\right|^{2} \Pi,+1,+\frac{1}{2}\right\rangle=i\left\langle B_{1},+\frac{1}{2}\left|\hat{H}_{S O, z}\right| B_{2},+\frac{1}{2}\right\rangle
\end{aligned}
$$

where $\mid$ state $, \Lambda, \Sigma\rangle$ are the $C_{\infty v}$ electronic wavefunctions [39, 40]. All the cal- 
culated SO-matrix elements and ladder operators are included to correctly simulate the complicated level structure due to the unpaired electronic spin in all the electronic states. The computed spin-orbit splitting for $\mathrm{A}^{2} \Pi v=0$ $(N=0)$ is $111 \mathrm{~cm}^{-1}$ which is within $2 \%$ of the current experimental value equals $108.1884(33) \mathrm{cm}^{-1}$. The spin-orbit couplings also have a strong effect on the ${ }^{4} \Sigma^{+}$state, which splits into two rather different potential curves with relatively large differences in dissociation energy $\left(D_{e}=109 \mathrm{~cm}^{-1}\right.$ for ${ }^{4} \Sigma_{1 / 2}^{+}$, $\mathrm{D}_{e}=131 \mathrm{~cm}^{-1}$ for $\left.{ }^{4} \Sigma_{3 / 2}^{+}\right)$.

Table 6: Ro-vibrational constants (in $\mathrm{cm}^{-1}$ ) of the $\mathrm{X}^{2} \Sigma^{+}, \mathrm{A}^{2} \Pi$ and $\mathrm{B}^{2} \Sigma^{+}$states of $\mathrm{AlD}^{+}$.

\begin{tabular}{|lllllllll|}
\hline State & $v$ & $T_{v}$ & $A_{v}$ & $A_{D, v}$ & $B_{v}$ & $10^{4} D_{v}$ & $10^{2} \gamma_{v}$ & $10^{2} p_{v}$ \\
\hline $\mathrm{X}^{2} \Sigma^{+}$ & 0 & 0.00 & & & 3.473406 & 1.1788 & 1.6048 & \\
& 1 & 1164.84 & & & 3.343229 & 1.2801 & 1.4882 & \\
& 2 & 2242.86 & & & 3.195912 & 1.4379 & 1.3522 & \\
& 3 & 3222.29 & & & 3.024578 & 1.7031 & 1.2057 & \\
& 4 & 4087.35 & & & 2.825036 & 2.1934 & 1.1404 & \\
$\mathrm{~A}^{2} \Pi^{\mathrm{b}}$ & 0 & 27710.29 & 111.1990 & 0.3332 & 3.539210 & 1.3202 & & -0.5577 \\
& 1 & 28950.05 & 110.4661 & 0.3197 & 3.445932 & 1.3193 & & 0.0823 \\
& 2 & 30143.91 & 109.8179 & 0.3054 & 3.352814 & 1.3338 & & 1.4970 \\
& 3 & 31288.30 & 112.4429 & 0.2647 & 3.377430 & 4.9506 & & -18.4957 \\
& 4 & 32397.10 & 107.6012 & 0.2829 & 3.172055 & 1.3978 & & -1.9759 \\
$\mathrm{~B}^{2} \Sigma^{+}$ & 0 & 31271.06 & & & 1.908245 & -8.2751 & 39.570 & \\
& 1 & 32209.06 & & & 2.142094 & 0.40465 & -2.7196 & \\
& 2 & 33131.25 & & & 2.119465 & 0.35930 & 5.1767 & \\
& 3 & 34030.64 & & & 2.095616 & 0.50149 & -1.5383 & \\
& 4 & 34905.07 & & & 2.068223 & 0.53319 & -1.2264 & \\
\hline
\end{tabular}

a Determined by [14] model fit to DUO [39] generated term values.

b For the $\mathrm{A}^{2} \Pi$ state: $A_{v}$ is the vibrational level dependent spin-orbit splitting, $A_{D, v}$ determines the rotational dependence, $\gamma_{v}$ is the spin-rotation constant, $p_{v}$ is the vibrational state dependent $\Lambda$-doublet parameter [14] that determines $\Delta F_{1,2}(J)$. 
The rovibrational terms of $\mathrm{a}^{2} \Sigma^{+}$state in $\mathrm{AlD}^{+}$may be described by [14]

$$
\begin{array}{ll}
F_{1, v}(N)=B_{v} N(N+1)-D_{v} N^{2}(N+1)^{2}+\gamma_{v} N & \text { where } N=J-\frac{1}{2} \\
F_{2, v}(N)=B_{v} N(N+1)-D_{v} N^{2}(N+1)^{2}-\gamma_{v}(N+1) & \text { where } N=J+\frac{1}{2}
\end{array}
$$

The corresponding spectroscopic constants for the $\mathrm{X}^{2} \Sigma^{+}$and $\mathrm{B}^{2} \Sigma^{+}$states are presented in Table 6. Those for vibrational levels $v=0$ and $v=1$ match the present experimental results very well although the computed spin-rotation constant is around a third smaller than the experimental value for the levels of $\mathrm{X}^{2} \Sigma^{+}$. The rovibrational terms of the $\mathrm{A}^{2} \Pi$ state in $\mathrm{AlD}^{+}$ require a more involved analysis, again following the method from [14]:

$$
T_{1,2}(N)=T_{v}+B_{v} x-D_{v} x^{2} \mp Z( \pm) \Delta F_{1,2}(J)
$$

where,

$$
\begin{aligned}
Z & =\left\{\frac{\left(A_{v}^{*}-2 B_{v}^{*}\right)^{2}}{4}-B_{v}^{*} x\right\}^{1 / 2} \\
\Delta F_{1,2}(J) & =\frac{1}{2} p_{v}\left(J+\frac{1}{2}\right)\left\{1 \pm\left(\frac{A_{v}^{*}-2 B_{v}^{*}}{2 Z}\right)\right\} \\
x & =\left(J+\frac{1}{2}\right)^{2}-1 \\
B_{v}^{*} & =B_{v}-2 D_{v} x \\
A_{v}^{*} & =A_{v}+A_{D, v} J(J+1)
\end{aligned}
$$

The ro-vibrational constants for $\mathrm{A}^{2} \Pi_{1 / 2} v=3$ clearly reveal there is substantial interaction predicted between this level and the lowest $\mathrm{B}^{2} \Sigma_{1 / 2}^{+} v=0$ vibronic level. This is unlikely to be a precise reflection of experiments because such interactions are typically sensitive at the sub-wavenumber level to the relative energies of the interacting ro-vibrational states. While a fitting can be made using the present $a b$ initio and spectroscopic data to refine the $\mathrm{A}^{2} \Pi_{1 / 2}$ potential this cannot be done for the $\mathrm{B}^{2} \Sigma_{1 / 2}^{+}$state as there is presently no spectroscopic information. The most significant omission is the energy minimum of the $\mathrm{B}^{2} \Sigma_{1 / 2}^{+}$potential and that is difficult to calculate to an accuracy better than $100 \mathrm{~cm}^{-1}$.

Another sensitive test of the potentials is a calculation of the $\Lambda$-doubling observed for the lowest excited ro-vibrational levels of the $\mathrm{A}^{2} \Pi_{1 / 2}$ and $\mathrm{A}^{2} \Pi_{3 / 2}$ states. This is achieved by including all $a b$ initio electronic states calculated 
and the relevant interaction matrix elements (spin-orbit coupling and the rotational-electronic Coriolis term.) This phenomenon is additionally very sensitive to the relative energies of the nearest ${ }^{2} \Sigma^{+}$and ${ }^{2} \Pi$ states. The resulting $\Lambda$-doubling predicted for both $v=0$ and $v=1$ vibrational levels of $\mathrm{A}^{2} \Pi$ is presented as a function of the rotational quantum number in Fig. 5(b).

Finally, the ro-vibrational constants in Table 6 are fit to simple polynomial expansions in $\left(v+\frac{1}{2}\right)^{n}$ and reported in Table 7 .

Table 7: Equilibrium constants (in $\mathrm{cm}^{-1}$ ) of the $\mathrm{X}^{2} \Sigma^{+}, \mathrm{A}^{2} \Pi$ and $\mathrm{B}^{2} \Sigma^{+}$states of $\mathrm{AlD}^{+}$.

\begin{tabular}{|llllllll|}
\hline State & $T_{e}$ & $\omega_{e}$ & $A_{e}$ & $B_{e}$ & $10^{4} D_{e}$ & $10^{2} \gamma_{e}$ & $10^{2} p_{e}$ \\
\hline $\mathrm{X}^{2} \Sigma^{+}$ & 0.00 & 1233.22 & & 3.5140 & 1.0705 & 1.6429 & \\
$\mathrm{~A}^{2} \Pi$ & 27681.21 & 1287.26 & 111.41 & 3.5855 & 1.3246 & & -1.9889 \\
$\mathrm{~B}^{2} \Sigma^{+}$ & 31403.91 & 954.89 & & 2.1753 & 0.3667 & -4.389 & \\
\hline
\end{tabular}

a Determined by $\left(v+\frac{1}{2}\right)^{n}$ polynomial fit to ro-vibrational constants of Table 6 .

Using the calculated TDMs (Fig. 3) the lifetime of the $v=0$ level in the $\mathrm{A}^{2} \Pi_{1 / 2}$ and $\mathrm{B}^{2} \Sigma_{1 / 2}^{+}$states was found to be $76 \mathrm{~ns}$ and $97 \mathrm{~ns}$, respectively. In addition, the decay from $\mathrm{A}^{2} \Pi_{1 / 2} v=0$ was $97.9 \%$ to the corresponding $v=0$ level of the ground state, confirming that this transition is highly diagonal [3]. By contrast, the majority of the decay from $\mathrm{B}^{2} \Sigma_{1 / 2}^{+} v=0$ is to three vibrational levels, namely $v=2(19 \%), v=3(49 \%)$ and $v=4$ $(23 \%)$ and some $7.8 \%$ to other vibrational levels. Although some decay was found to the $\mathrm{A}^{2} \Pi_{1 / 2}$ state, this did not exceed $0.001 \%$. However, the present simulations only consider radiative decay and as the $\mathrm{A}^{2} \Pi_{1 / 2} v=0$ level lies over twenty thousand wavenumbers above the first dissociation limit, it could be adversely affected by predissociation [3], unlike the corresponding $\Pi \leftarrow \Sigma^{+}$transition in AlD [2]. A calculation of Nguyen et al. [3] for $\mathrm{AlH}^{+}$ suggests that this rate is indeed negligible, around $0.2 \pm 0.1 \mathrm{~s}^{-1}$.

\section{7. $\Lambda$-doubling of the $\mathrm{A}^{2} \Pi v=0,1$ levels}

The ${ }^{2} \Pi \sim{ }^{2} \Sigma^{+}$interaction, which is different for the $e$ and $f$ levels, gives rise to $\Lambda$-doubling in the ${ }^{2} \Pi$ and spin-doubling of the ${ }^{2} \Sigma^{+}$state [38]. Moreover, the different kinds of ${ }^{2} \Pi_{1 / 2} \sim{ }^{2} \Sigma^{+}$and ${ }^{2} \Pi_{3 / 2} \sim{ }^{2} \Sigma^{+}$interactions cause that the value of the $\Lambda$-doubling splitting is different for the two 
substates of the ${ }^{2} \Pi$ state [38]. For the ${ }^{2} \Pi_{1 / 2}$ the $\Delta \mathrm{F}_{f e}$ value should be zero at the origin, then negative with increasing $J$, and finally rise to positive values. For the ${ }^{2} \Pi_{3 / 2}$ substate the $\Delta \mathrm{F}_{f e}$ should rise slowly from zero at small $J$ [41]. Thus for large enough $J$ it has the same sign (and similar value) for the $F_{1}$ and $F_{2}$ terms [37].

For the $\mathrm{AlD}^{+} \mathrm{A}^{2} \Pi$ state $\Lambda$-doubling should arise mainly from the interaction with the nearby $\mathrm{B}^{2} \Sigma^{+}$state. The present $a b$ initio calculations locate the $\mathrm{B}^{2} \Sigma^{+}$state about $3720 \mathrm{~cm}^{-1}$ above from the $\mathrm{A}^{2} \Pi$ state (see Table 7 ). However, the simple pure precession estimation in Section 5.3 and present $a b$ initio results do not give a full understanding of this interaction. The observed $\Lambda$-doubling of the $\mathrm{A}^{2} \Pi v=0,1$ levels is presented in Fig. 5(a) and compared with theoretical prediction in Fig 5(b).

(a)
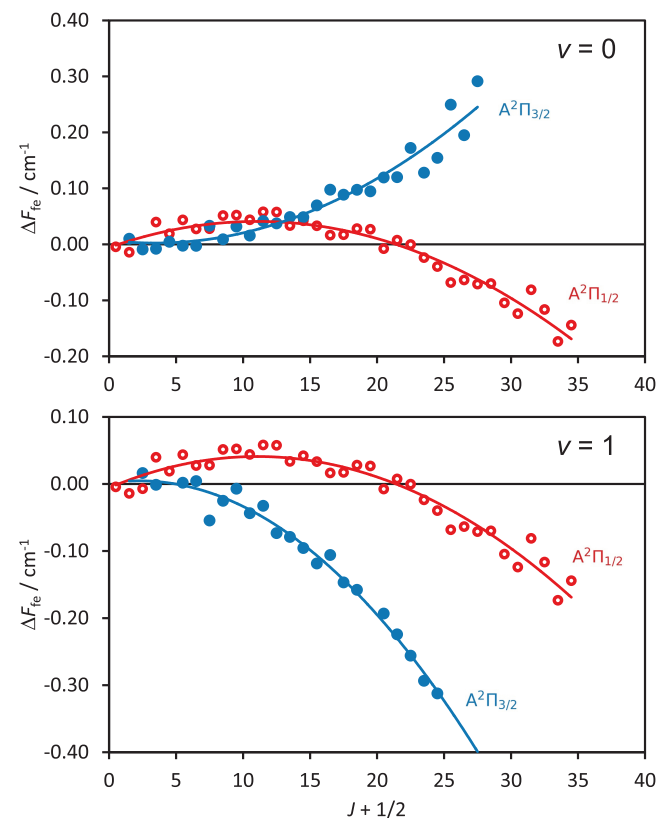

(b)
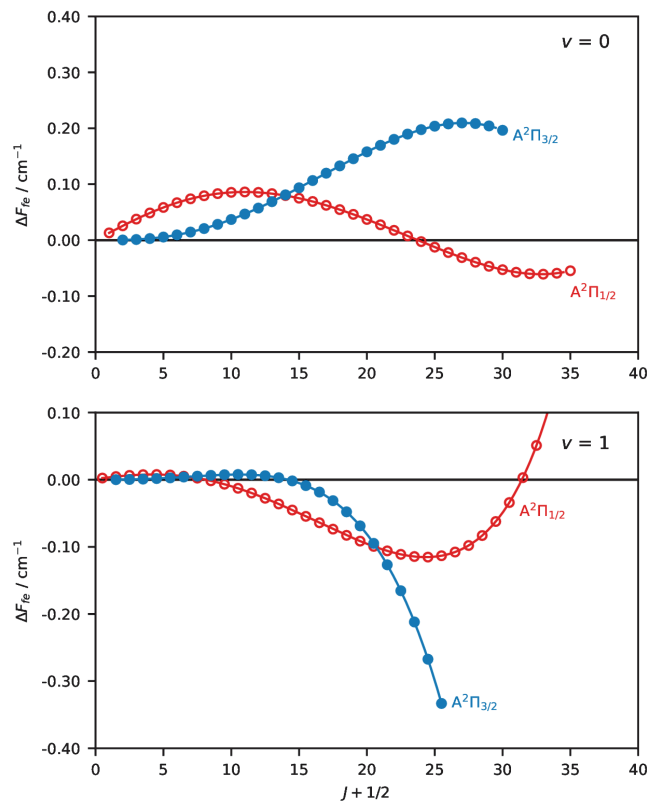

Figure 5: The $\Lambda$-doubling of the $\mathrm{A}^{2} \Pi v=0,1$ levels of $\mathrm{AlD}^{+}$: (a) observed on the basis of the term values from Table 4, (b) calculated using the potentials from Fig. 2.

The calculated $J$-dependence is in excellent agreement with the experimental values in Fig. 5(a) for $v=0$, both in general trends and absolute value. However, the calculated splitting for $v=1$, while still in reasonable agreement, clearly does not reproduce the observed $J$-dependence as ac- 
curately. Moving the $\mathrm{B}^{2} \Sigma^{+}$state potential relative to the $\mathrm{A}^{2} \Pi$ state by as much as $\pm 200 \mathrm{~cm}^{-1}$ did not strongly improve this result. Shifting the potential up improves slightly the agreement for $\mathrm{A}^{2} \Pi_{1 / 2} v=1$, while shifting down strongly improves $\mathrm{A}^{2} \Pi_{3 / 2} v=1$ at the expense of $\mathrm{A}^{2} \Pi_{1 / 2}(v=0$ is not really changed). It looks like a simple shift wont solve this and the potential would have to be more accurate - a very long project. - I took this sentences from your "Notes...". Please improve this, it may be some kind of summary. What do you think?

\section{Conclusions}

The emission VIS spectrum of the $\mathrm{AlD}^{+}$isotopologue was recorded with a Fourier transform spectrometer for the first time. The $(0,0)$ and $(1,1)$ bands belonging to the $\mathrm{A}^{2} \Pi-\mathrm{X}^{2} \Sigma^{+}$electronic transitions were identified and analyzed. The $\Lambda$-doubling of the $\mathrm{A}^{2} \Pi v=0,1$ levels has been studied on the basis of the experimental rotational term values. Molecular constants of the $\mathrm{X}^{2} \Sigma^{+}$state have been obtained by method based on the Curl and Dane [28] and Watson [29] approach. Ab initio calculations reproduce these results very well including the $\Lambda$-doubling observed for the lowest vibrational level of the excited $\mathrm{A}^{2} \Pi$ state. The highly diagonal nature of the $\mathrm{A}^{2} \Pi-\mathrm{X}^{2} \Sigma^{+}$ transition coupled with its relatively short lifetime suggests $\mathrm{AlD}^{+}$is a good laser cooling prospect, though it is critical that any predissociation loss is below $0.01 \%$ or the cooling will be terminated within $10^{4}$ cycles.

\section{Acknowledgments}

WSz express his gratitude for the support of the European Regional Development Fund and the Polish state budget within the framework of the Carpathian Regional Operational Programme (RPPK.01.03.00-18-001/10) for the period $2007-2013$ through the funding of the Centre for Innovation and Transfer of Natural Science and Engineering Knowledge of the University of Rzeszów. ICL thanks the Leverhulme Trust (Research Grant RPG-2014212) for financial support including the funding of a studentship for KM.

\section{References}

[1] Di Rosa MD. Laser-cooling molecules. Eur Phys J D 2004;31:395-402. 
[2] Wells N, Lane IC. Electronic states and spin-forbiden cooling transitions of AlH and AlF. Phys Chem Chem Phys 2011;13:19018-25.

[3] Nguyen JHV, Viteri CR, Hohenstein EG, Sherrill CD, Brown KR, Odom B. Challenges of laser-cooling molecular ions. New J Phys 2011;13:063023.

[4] Lien CY, Williams SR, Odom B. Optical pulse-shaping for internal cooling of molecules. Phys Chem Chem Phys 2011;13:18825-29.

[5] Seck CM, Hohenstein EG, Lien CY, Stollenwerk PR, Odom B. Rotational state analysis of $\mathrm{AlH}^{+}$by two-photon dissociation. J Mol Spectrosc 2014;300:108-11.

[6] Lien CY, Seck CM, Lin YW, Nguyen JHV, Tabor DA, Odom B. Broadband optical cooling of the molecular rotors from room temperature to the ground state. Nat Commun 2014;5:4783.

[7] Szajna W, Zachwieja M. Emission spectroscopy of the $\mathrm{A}^{1} \Pi-\mathrm{X}^{1} \Sigma^{+}$ system of AlH. Eur Phys J D 2009;55:549-55.

[8] Szajna W, Zachwieja M. The emission spectrum of the $\mathrm{C}^{1} \Sigma^{+}-\mathrm{X}^{1} \Sigma^{+}$ system of AlH. J Mol Spectrosc 2010;260:130-4.

[9] Szajna W, Zachwieja M, Hakalla R, Kępa R. Emission spectroscopy of $\mathrm{AlH}$ : the $\mathrm{X}^{1} \Sigma^{+}, \mathrm{A}^{1} \Pi$ and $\mathrm{C}^{1} \Sigma^{+}$states characteristics. Acta Phys Pol A 2011;120:417-23.

[10] Szajna W, Hakalla R, Kolek P, Zachwieja M. The new investigation of the $b^{3} \Sigma^{-}-a^{3} \Pi$ system of AlH. J Quant Spectrosc Radiat Transf 2017;187:167-77.

[11] Szajna W, Zachwieja M. High-resolution emission spectroscopy of the $\mathrm{A}^{2} \Pi-\mathrm{X}^{2} \Sigma^{+}$system of $\mathrm{AlH}^{+}$. J Mol Spectrosc 2011;269:56-60.

[12] Szajna W, Zachwieja M, Hakalla R. Rotational analysis of the $0-0$ and $1-1$ bands of the $\mathrm{A}^{1} \Pi-\mathrm{X}^{1} \Sigma^{+}$system of the AlD isotopologue. J Mol Spectrosc 2015;318:78-83.

[13] Szajna W, Moore K, Lane IC. The emission spectroscopy of AlD in the visible region: experimental and theoretical investigations. J Quant Spectrosc Radiat Transf 2017;196:103-11. 
[14] Balfour WJ, Lindgren B. The $\mathrm{A}^{2} \Pi-\mathrm{X}^{2} \Sigma$ system od $\mathrm{AlD}^{+}$and $\mathrm{C}^{1} \Sigma-\mathrm{A}^{1} \Pi$ system of AlD. J Phys B: At Mol Phys 1984;17:L861.

[15] Klein R, Rosmus P, Werner HJ. Ab initio calculations of low lying states of the $\mathrm{BH}^{+}$and $\mathrm{AIH}^{+}$ions. J Chem Phys 1982;77:3559-70.

[16] Woon DE, Dunning Jr TH. Gaussian Basis Sets for Use in Correlated Molecular Calculations. III. The second row atoms, Al-Ar. J Chem Phys 1993;98:1358-1371.

[17] Siegbahn P, Heiberg A, Roos B, Levy B. A Comparison of the Super-CI and the Newton-Raphson Scheme in the Complete Active Space SCF Method. Phys Scr 1980;21:323-30.

[18] Gui-Xia L, Tao G, Yun-Guang Z. The splitting of low-lying or low excited states for hydride molecules (cations) of the third period under spin-orbit coupling. Chin Phys Soc 2008;17:2040-8.

[19] Peterson KA, Dunning Jr TH. Accurate correlation consistent basis sets for molecular core-valence correlation effects. The second row atoms $\mathrm{Al}-\mathrm{Ar}$, and the first row atoms $\mathrm{B}-\mathrm{Ne}$ revisited. J Chem Phys $2002 ; 117: 10548-647$.

[20] Lagerqvist A, Lundh LE, Neuhaus H. A grating order sorter for separation of high orders in a $5 \mathrm{~m}$ fastie vacuum spectrograph. Phys Scri 1970;1:261-6.

[21] OPUS ${ }^{\mathrm{TM}}$, Computer program by Bruker Optik GmbH 2014, v.7.5.18.

[22] Palmer BA, Engleman R. Atlas of the thorium spectrum. New Mexico: Los Alamos Report LA-9615. Los Alamos: Los Alamos Scientific Laboratory; 1983.

[23] Herzberg G. Molecular spectra and molecular structure. I. Spectra of Diatomic Molecules. New York, United States of America: Van Nostrand-Reinhold; 1950.

[24] Werner HJ, Knowles PJ, Knizia G, Manby FR et al., MOLPRO; 2010, http://www.molpro.net. 
[25] Werner HJ, Knowles PJ. An efficient internally contracted multiconfiguration reference configuration interaction method. J Chem Phys 1988;89:5803-8.

[26] Langhoff S, Davidson ER. Configuration interaction calculations on the nitrogen molecule. Int J Quantum Chemistry 1974;8:61-8.

[27] Berning A, Schweizer M, Werner HJ, Knowles PJ, Palmeri P. Spin-orbit matrix elements for internally contracted multireference configuration interaction wavefunctions. Mol Phys 2000;98:1823-28.

[28] Curl RF, C.B. Dane CB. Unbiased least-squares fitting of lower states. J Mol Spectrosc 1988; 128:406-12.

[29] Watson JKG. On the use of term values in the least-squares fitting of spectra. J Mol Spectrosc 1989;138:302-8.

[30] Brown JM, Colbourn EA, Watson JKG, Wayne FD. An effective Hamiltonian for diatomic molecules: ab initio calculations of parameters of $\mathrm{HCl}^{+}$. J Mol Spectrosc 1974;74:294-318.

[31] Amiot C, Maillard JP, Chauville J. Fourier spectroscopy of the OD infrared spectrum. Merge of electronic, vibration-rotation, and microwave spectroscopic data. J Mol Spectrosc 1981;87:196-218.

[32] Douay M, Rogers SA, Bernath PF. Infrared Fourier transform spectroscopy of XeH. Mol Phys 1988;64:425-36.

[33] Western CM. PGOPHER: A program for simulating rotational, vibrational and electronic spectra. J Quant Spectrosc Radiat Transf 2017;186:221-42 (http://pgopher.chm.bris.ac.uk).

[34] Veseth L. Modifications of the doublet energy formulae of a diatomic molecule necessitated by the rotational stretching. J Phys B: At Mol Phys 1970;3:1677-91.

[35] Brown JM, Watson JKG. Spin-spin and spin-rotation coupling in doublet states of diatomic molecules. J Mol Spectrosc 1977;65:65-74.

[36] Müller B, Ottinger C. Über die spektroskopischen konstanten des $\mathrm{A}^{2} \Pi-$ und $\mathrm{X}^{2} \Sigma^{+}$-zustandes von $\mathrm{AlH}^{+}$. Z Naturforsch 1988;43:1007-8. 
[37] Mulliken RS, Christy A. $\Lambda$-type doubling and electron configurations in diatomic molecules. Phys Rev 1931;38:87-119.

[38] Lefebvre-Brion H, Field RW. The spectra and dynamics of diatomic molecules. Amsterdam, The Netherlands: Elsevier Academic Press; 2004.

[39] Yurchenko SN, Lodi L, Tennyson J, Stolyarov AV. Duo: A general program for calculating spectra of diatomic molecule. Comp Phys Comm 2016;202:262-75.

[40] Patrascu AT, Hill C, Tennyson J, Yurchenko SN. Study of the electronic and rovibronic structure of the $\mathrm{X}^{2} \Sigma^{+}, \mathrm{A}^{2} \Pi$ and $\mathrm{B}^{2} \Sigma^{+}$states of $\mathrm{AlO}$. J Chem Phys 2014;141:144312.

[41] Almy GM, Watson MC. The band spectrum of ionized aluminum hydride. Phys Rev. 1934;45:871-6. 